Florida International University FIU Digital Commons

$6-27-2017$

\title{
The Always on Employee: The Antecedents and Consequences of Work-Related Email Use After Hours
}

Archana Manapragada

Florida International University, amana008@fiu.edu

DOI: $10.25148 /$ etd.FIDC001945

Follow this and additional works at: https://digitalcommons.fiu.edu/etd

Part of the Industrial and Organizational Psychology Commons

\section{Recommended Citation}

Manapragada, Archana, "The Always on Employee: The Antecedents and Consequences of Work-Related Email Use After Hours" (2017). FIU Electronic Theses and Dissertations. 3393.

https://digitalcommons.fiu.edu/etd/3393 


\title{
FLORIDA INTERNATIONAL UNIVERSITY
}

\author{
Miami, Florida
}

THE ALWAYS ON EMPLOYEE: THE ANTECEDENTS AND CONSEQUENCES OF WORK-RELATED EMAIL USE AFTER HOURS

A dissertation submitted in partial fulfillment of the

requirements for the degree of

DOCTOR OF PHILOSOPHY

in

PSYCHOLOGY

by

Archana Manapragada

2017 
To: Dean Michael R. Heithaus

College of Arts, Sciences, and Education

This dissertation, written by Archana Manapragada, and entitled The Always on Employee: The Antecedents and Consequences of Work-Related Email Use After Hours, having been approved in respect to style and intellectual content, is referred to you for judgment.

We have read this dissertation and recommend that it be approved.

Valentina Bruk Lee

Asia Eaton

Nathan Hiller

Chockalingam Viswesvaran, Major Professor

Date of Defense: June 27, 2017

The dissertation of Archana Manapragada is approved.

Dean Michael R. Heithaus

College of Arts, Sciences, and Education

Andrés G. Gil

Vice President for Research and Economic Development and Dean of the University Graduate School

Florida International University, 2017 


\author{
ABSTRACT OF THE DISSERTATION \\ THE ALWAYS ON EMPLOYEE: THE ANTECEDENTS AND CONSEQUENCES OF \\ WORK-RELATED EMAIL USE AFTER HOURS \\ by \\ Archana Manapragada \\ Florida International University, 2017 \\ Miami, Florida \\ Professor Chockalingam Viswesvaran, Major Professor
}

The present dissertation examines the antecedents and consequences of employees' workrelated email (WRE) use after work hours in a sample of administrative assistants and office workers. Several individual, job, and workplace factors were examined as predictors of WRE use after hours. The individual-level factors examined were telepressure (i.e., the urge to respond to digital messages) and conscientiousness. Perceptions of the usefulness of keeping up with WRE for job performance and the degree to which employees felt the use of WRE was relevant to their job were examined as job-related factors. Workplace factors revolved around organizational norms, which may form by employees' perceptions of their supervisors' or coworkers' use of WRE after hours and their perceptions of the extent to which they were expected to keep up with their WRE after hours. All antecedents, except conscientiousness, had a positive relationship with WRE use after hours, and telepressure, job relevance, and perceived usefulness were found to predict unique variance in WRE use after hours.

Burnout was examined as a consequence of WRE use after hours. Although positive relationships between WRE use after hours and burnout dimensions were hypothesized, 
results showed that emotional exhaustion did not significantly relate to WRE use after hours, and cynicism and reduced professional accomplishment had a negative relationship with WRE use after hours. These findings suggest that keeping up with WRE after hours may be a method to manage work demands rather that act as a source of additional work demands.

Voluntariness was found to moderate WRE use after hours' relationships with emotional exhaustion and reduced professional accomplishment, suggesting that if employees feel the use of WRE after hours is non-mandatory, they are likely to experience more positive wellbeing outcomes as a result of keeping up with their WRE after hours. The findings of the present dissertation make a unique contribution to an emerging area of literature, and allow researchers and practitioners to gain better insight into factors that can influence employees' WRE use after hours, possible consequences of keeping up with WRE, and factors that can influence the relationship between WRE use after hours and burnout. 


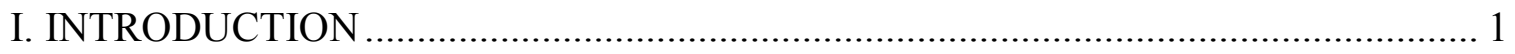

Antecedents of Work-Related Email Use After Hours............................................. 5

Work-Related Email Use After Hours and Burnout ................................................... 9

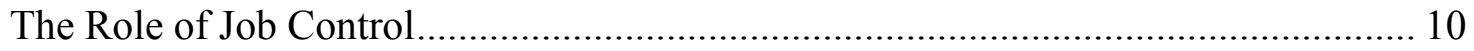

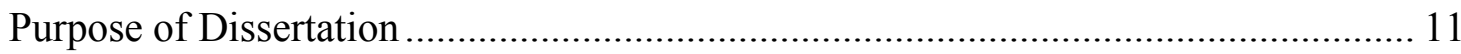

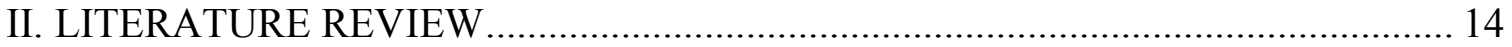

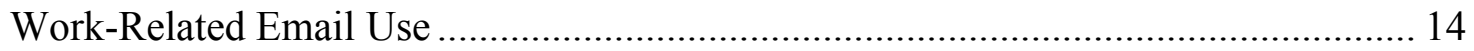

Antecedents of Work-Related Email Use After Hours.................................................. 18

Consequences of Work-Related Email Use After Hours............................................. 35

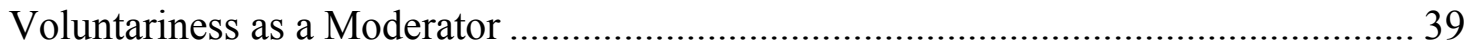

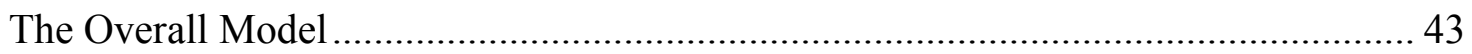

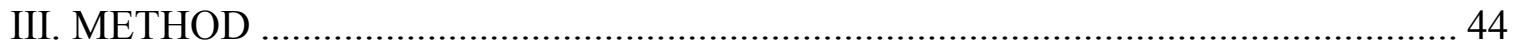

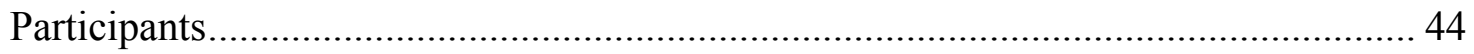

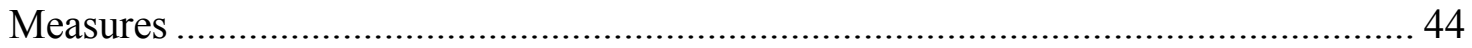

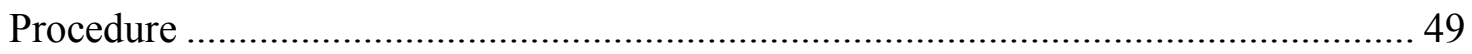

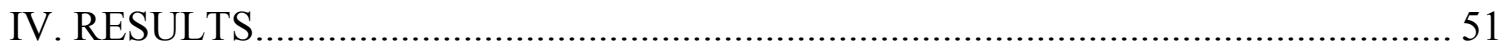

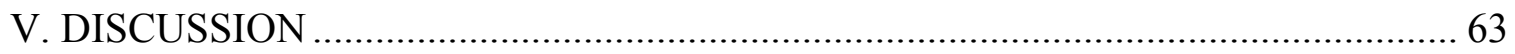

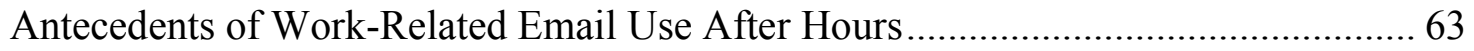

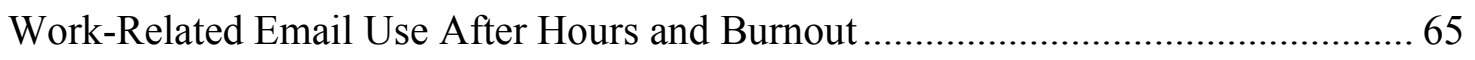

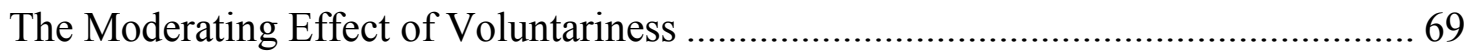

Work-Related Email Use After Hours and Demographic Characteristics.................... 70

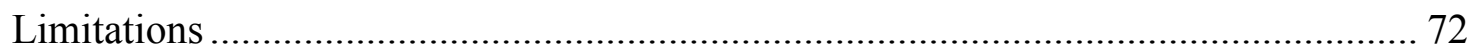

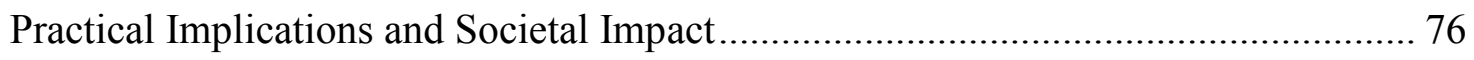

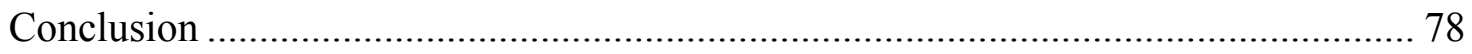

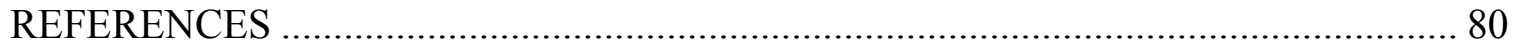

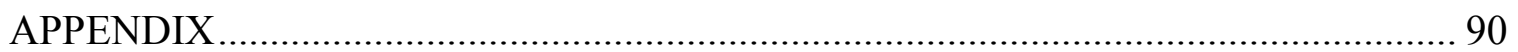

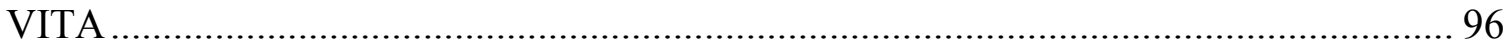




\section{LIST OF FIGURES}

FIGURES

PAGE

1. The proposed model...................................................... 3

2. The full model of proposed antecedents, consequences, and moderator

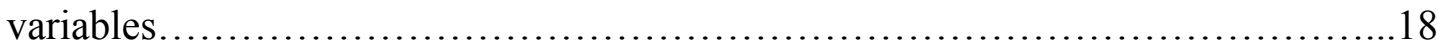

3. The ecological systems model...........................................20

4. Outcomes of interactions between job demands and job resources...................41

5. The moderating effect of voluntariness on the relationship between emotional exhaustion and WRE use after hours..............................58

6. The moderating effect of voluntariness on the relationship between reduced personal accomplishment and WRE use after hours 


\section{INTRODUCTION}

The advancement of technology has led to a proliferation of smartphones, tablets, and other portable communication devices, making it easier for employees to work from anywhere at any time. Electronic mail (email), in particular, has revolutionized the communication of workplace information. Employees use email for daily tasks such as distributing human resource memos, scheduling meetings, distributing drafts of projects and proposals, following up on meetings, and even sending invitations to office holiday parties. Most workplace communication today involves the use of email.

From its inception in the 1970s, the use of email for business purposes has been on a consistent rise. A 12-year old study examining the use of work-related email found that individuals send approximately 14 emails, read 30 emails, and check their email inbox 19 times per day (Dabbish et al., 2005). In 2015, the daily number of businessrelated emails sent and received per person per day was estimated to be 122, and by 2019 , that frequency is predicted to increase to 126 emails per day (The Radicati Group, 2015). This steady rise in email usage calls for further exploration into the effects of constant business-related communication on employees' health and well-being.

Although email has created a boom in productivity by allowing employees to better meet work demands, the ease and flexibility of email usage has blurred the lines between employees' work and home domains (Boswell \& Olson-Buchanan, 2007; Clark, 2002; Golden, 2013; Towers, Duxbury, Higgins, \& Thomas, 2006). Indeed, survey results by the American Psychological Association's Center for Organizational Excellence (2013) show that $52 \%$ of adults check work-related emails, text messages, and/or voicemails before or after work hours, $54 \%$ stay connected to the workplace via 
technology while sick at home, and $44 \%$ use communication technology for work-related purposes while on vacation. Unfortunately, given the rapid development of new technologies, the effects of these technologies on individuals' psychological health has not received adequate empirical investigation by researchers.

After business hours, employees may consider emailing to be the preferred method of contact with coworkers, supervisors, or clients, since it is perceived to be less invasive than phone calls or text messages. However, receiving emails has become almost as invasive as receiving a text message or phone call if the user allows it to be. For example, email users may choose to link their work-related email accounts to their smartphones, tables, and other portable mobile devices, allowing them to access it from anywhere at any time. In essence, email acts as a constant psychological link to the workplace, even after employees are "off the clock," given that one must stay mentally alert and aware of workplace matters while reading or responding to work-related emails. This psychological link to the workplace may cause employees to feel that they are "always on," which can drastically reduce the number of opportunities available to recuperate mental and physical energy after meeting work demands during business hours.

The focal variable in this dissertation is work-related email (WRE) use after work hours, given that email is one of the most consistent and common methods of communication among coworkers, supervisors, and clients, especially outside of work. After hour WRE use can be described as sending, reading, or checking emails relating to one's job during "off the clock" hours. For example, if an employee works a shift from 9 $\mathrm{AM}$ to $5 \mathrm{PM}$, reading or responding to work email before $9 \mathrm{AM}$ or after $5 \mathrm{PM}$ would be 
considered WRE use after hours. Sending and checking email during the weekend, while taking sick days, or on days off is also considered to be using WRE after hours. In addition, WRE use after hours refers to any emails relating to job tasks, such as sending emails to or reading emails from supervisors, coworkers, clients, or other work-related contacts.

The aim of the present study is to examine the antecedents and consequences of WRE use after work hours. More specifically, individual, job, and workplace factors will be examined as predictors of WRE use after hours, and burnout will be examined as an outcome. In addition, the influence of a specific form of job control (i.e., voluntariness), will be examined as a moderator of the relationship between WRE use after hours and burnout (see Figure 1).

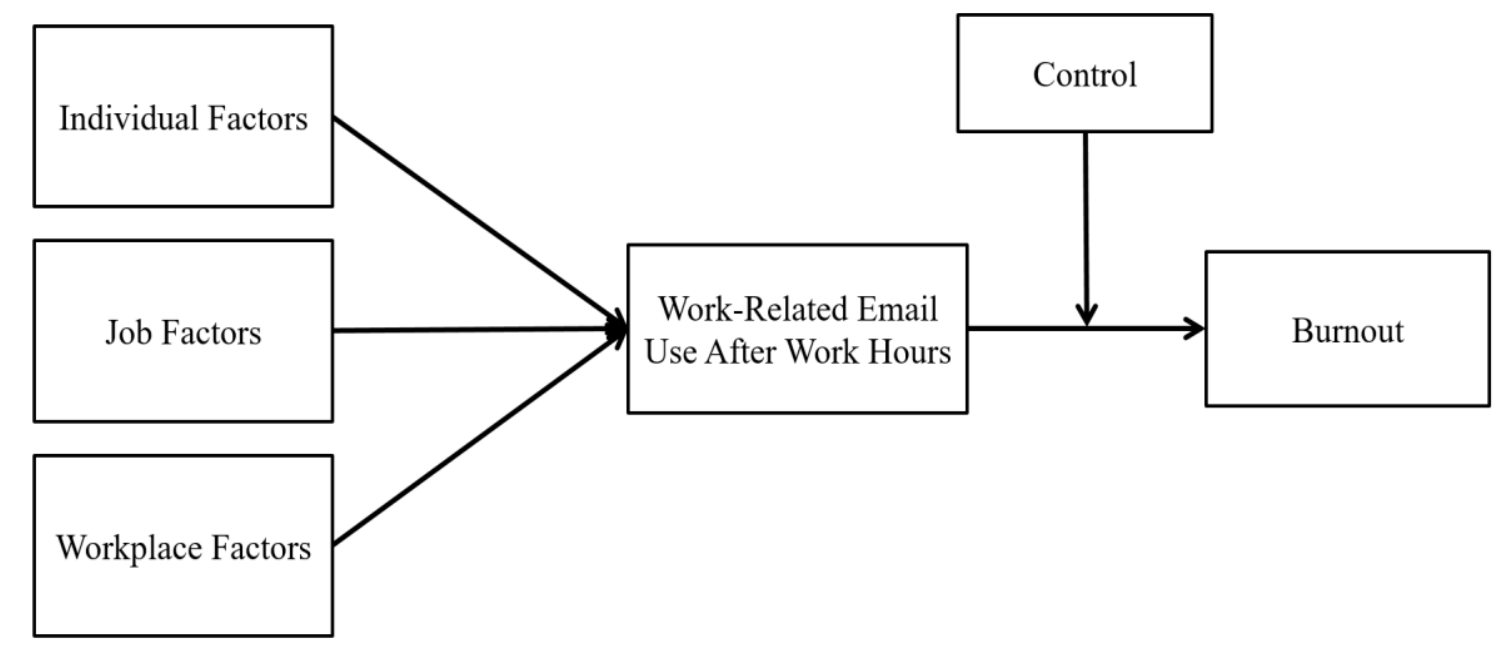

Figure 1. The proposed model.

The proposed model will be tested in a sample of office workers and administrative assistants, which is an ideal sample to assess these relationships. First, 
office workers and administrative assistants are likely to have clear working hours (e.g., 9 AM to $5 \mathrm{PM}$ ), making it easy to measure the amount of time spent keeping up with WRE after business hours. In addition, the role of an office worker has greatly evolved over the past few decades. The pressure for organizations to make budget cuts has caused a drastic increase in the workload put on office workers and administrative assistants. Now, not only are office workers and administrative assistants responsible for clerical duties, but may also have responsibilities related to customer service, human resources, or office management. In addition, employees are often dependent upon office workers to cater to immediate needs, making the job one of high-stress. Finally, email is a critical component of the job in this field. Office workers heavily rely on email, with $86 \%$ of secretaries and administrative assistants reporting using email every day (O*NET Online, 2015). Given the high pressure, high stress, and heavy workload experienced in this field, office workers may be likely to allow work to spill over into nonwork domains through the use of WRE after hours.

For the remainder of this chapter, a more specific description of each predictor and outcome variable will be given. The workplace antecedents being discussed are subjective expectations of WRE use and supervisor/coworker WRE use. Job factors such as perceived usefulness and job relevance will also be described, along with telepressure and conscientiousness, which are the two individual factors included in the model. The proposed relationship between WRE use after hours and burnout will then be discussed, along with voluntariness, which is being examined as a moderator. Following a summary of the model variables, a summary of the purpose of this dissertation will be given, which includes a discussion of the theoretical and practical contributions of this study. 


\section{Antecedents of Work-Related Email Use After Hours}

To date, the majority of organizations in the United States have taken no concrete initiatives regarding the use of WRE after hours. There are measures being taken by companies and nations in Europe, however, aimed at restricting the use of out-of-hours email. In 2017, France passed a "right to disconnect" law requiring companies with over 50 employees to identify hours during which employees are not to send or respond to work-related emails. A few European companies such as Volkswagen, BMW, and Puma, for example, have taken initiatives targeting the reduction of employee use of WRE after hours. After receiving complaints from workers that keeping up with emails after work hours was blurring the boundary between their work and home lives, Volkswagen established a policy in which company email servers start routing emails only 30 minutes before the start of the workday and stop 30 minutes after the end of the workday. This system allows workers to have downtime while they are "off the clock" to psychologically detach from work and recover mental resources expended during the workday.

In most organizations, in lieu of relying upon organizational policies, there may be several factors that play a role in one's decision to keep up with WRE after hours. For example, employees may be more dependent on social cues in such organizations to determine whether emailing after work hours is appropriate. Indeed, social learning theory suggests that individuals tend to imitate behaviors displayed by others in their social group (Bandura, 1977). When deciding whether to keep up with WRE after hours, individuals may also consider the benefit of doing so for their job performance, whether they are expected to keep with emails after work, and whether it is convenient for them to 
do so. In addition, individuals' psychological states and personality traits can also influence whether they engage in WRE after hours.

Given that relationships between individuals and their environments are complex, and that several environmental factors can interact to influence human behavior, the antecedents being examined in this study are organized into a three-level hierarchy using Bronfenbrenner's (1977) ecological model as a foundation for this framework. Human behavior is complex and dynamic, and therefore, the ecological systems theory proposes that no single factor predicts human behavior as accurately as a combination of factors across different levels. The present dissertation proposes that factors at individual, job, and workplace levels can all play a role in influencing an individual's decision to read, send, or check their WRE after work hours. Individual factors consist of any personality traits or psychological states that can influence an employee's decision to keep up with their WRE after hours. Job factors can be defined as elements of employees' overall work or work tasks that play a role in their use of WRE after hours. Workplace factors include any components of an individual's workplace and/or the behavior of individuals that are representative of the organization as a whole (e.g., supervisor or coworkers' behavior). Table 1 below presents all antecedents of WRE use after hours being examined in this study.

Table 1. Antecedents of WRE use after hours.

\begin{tabular}{lll}
\hline Individual Factors & Job Factors & Workplace Factors \\
\hline Telepressure & Perceived Usefulness & Expectations of use \\
Conscientiousness & Job Relevance & Supervisor/coworker use \\
\hline
\end{tabular}


Individual factors. Employees' personal characteristics are likely to play a significant role in determining whether they keep up with WRE after work hours. The two individual factors being examined in this study are telepressure, which is a mental state, and conscientiousness, which is a personality trait. Telepressure can be defined as psychological state characterized by a preoccupation with and urge to respond to workrelated messages from supervisors, coworkers, or clients. Employees who have trouble concentrating on other activities or have overwhelming feelings to respond when they receive work-related messages are said to have high levels of telepressure (Barber \& Santuzzi, 2014). Telepressured employees are more likely respond to WRE after hours in order to placate their urge to respond to such messages immediately. In addition, telepressured employees tend to constantly think about responding to work-related messages until they meet their urge to respond.

Conscientious workers can be described as employees that are achievementoriented, responsible, dependable, and practical (Goldberg, 1992). Conscientious individuals who are striving towards a work goal, whether it be a promotion, a good recommendation from a supervisor, or rewards/recognition, may be more likely to send and respond to WRE after hours if they believe it will help in achieving their goal. In addition, if highly conscientious employees receive emails from supervisors or coworkers after work hours, they may be more likely to respond due to their reliable and responsive nature (Barber \& Santuzzi, 2014).

Job factors. Employees' views on sending and responding to WRE after hours can also influence their decision to engage in this behavior. Perceived usefulness, which is the degree to which an individual feels that the use of a certain technology will enhance 
his or her job performance (Venkatesh \& Davis, 2000), can play a key role in whether employees actually engage in WRE use after hours. If employees believe that sending and responding to WRE while at home increases their productivity and effectiveness in their job, they may be more likely to use WRE at home.

Another predictor of WRE use after hours may be job relevance, or the degree to which employees consider the use of a technology to be important and relevant to their job (Venkatesh \& Davis, 2000). Employees who do not consider the use of WRE after hours to be important are less likely to keep up with WRE at home. For example, if a workplace does not heavily rely on email as a communication tool, making the use of WRE less relevant to the job, employees may be less likely to check their work emails after hours.

Workplace factors. Factors related to one's perceptions of what occurs in an organization or what is expected of employees in an organization can greatly impact whether employees engage in WRE after hours. Perceptions of supervisors' and coworkers' use of WRE after hours, for example, can act as an indicator of workplace norms. If employees observe their supervisors and/or coworkers sending or checking WRE after hours, they may be more likely to engage in this behavior themselves. Perceptions of others' WRE use after hours are arguably more influential than actual use of WRE after hours, since employees are likely to base their behavior on what they speculate others in their workplace to be doing. For example, if an employee receives an email from a supervisor on the weekend during non-business hours, that employee may perceive their supervisor as always active on work email over the weekend, even though that may not necessarily be the case. 
If employees are on the receiving end of WRE after hours, especially from supervisors or coworkers that influence their behavior, they may feel obligated to respond. In essence, employees may be especially likely to keep up with WRE after hours if they feel that others expect them to do so. These perceptions can be described as subjective expectations of use (Venkatesh \& Davis, 2000), which can be characterized as the degree to which an individual feels that WRE usage after hours is expected by those who are important to them and/or influence their behavior, such as supervisors or coworkers.

\section{Work-Related Email Use After Hours and Burnout}

The outcome of interest in the proposed model is employee burnout, which can be described as a distressed psychological state in which the resources required to meet the demands of a job exceed the available resources possessed by an individual. Burnout has three main components: emotional exhaustion, cynicism, and a reduced sense of personal accomplishment. Emotional exhaustion can be defined as the depletion of mental energy. When individuals lack the resources to meet high work demands, they may experience feelings of overexertion, which may result in them feeling that they are unable to recover from this exhausted state. Cynicism, which is also referred to as depersonalization, is characterized by individuals distancing themselves from their work, which can lead them to develop negative feelings towards work itself. Personal accomplishment can be defined as a sense of competence and professional efficacy, which can be diminished when individuals perceive a lack of resources in meeting job demands (Maslach, Schaufei \& Leiter, 2001). 
The job demands-resources model suggests that burnout results from an imbalance between job demands and the resources available to take on those demands. Job resources are defined as any physical, organizational, social, or psychological factors that help in achieving work goals, reducing job demands, or stimulating personal growth (Demerouti, Bakker, Nachreiner, Schaufeli, 2001). Job resources include variables such as job control, social support, rewards, and role clarity, among others (Demerouti et al., 2001; Lee \& Ashforth, 1996). When individuals experience a lack of resources, they have a reduced ability to cope with job demands (e.g., heavy workloads), which can result in burnout.

Keeping up with WRE after work hours can result in a self-assigned increase in workload, since individuals are essentially engaging in activities or conducting job tasks that should be done during business hours. Indeed, workload has consistently been found to predict employee burnout (Corders \& Dougherty, 1993; Lee \& Ashforth, 1996). In addition, WRE use after hours can drastically reduce the number of opportunities available to an employee to psychologically detach from work and replenish lost resources, such as time and energy spent during the workday. A multitude of research has shown that failing to recover from the investment of mental and/or physical resources results in fatigue and other negative health symptoms (Beehr et al., 2010; Lee \& Ashforth, 1996).

\section{The Role of Job Control}

Job control can generally be defined as the degree to which employees feel that they have influence over their work environment (Ganster, 1989), such as their roles, 
tasks, and quality of work (Dwyer \& Ganster, 1991). According to the job demandsresources model, job control is considered a resource that can offset the negative effects of workplace stressors. In other words, job control is thought to weaken the relationships between job demands and various negative outcomes. Indeed, job control has often been found to buffer the relationship between various job demands and employee burnout (Xanthopoulou, Bakker, Demerouti, \& Schaufeli, 2007). Therefore, employees who experience high levels of job control may be less likely to experience burnout as a result of heavy job demands.

Voluntariness can be defined as the degree to which individuals perceive the use of a certain technology to be non-mandatory (Hartwick \& Barki, 1994; Venkatesh \& Davis, 2000). Voluntariness can be considered a more specific form of job control over work-related tasks that is directly relevant to the use of work-related technology after work hours. If individuals experience high voluntariness, they feel that they are given greater decision latitude over whether they keep up with WRE after work hours. If employees feel that they are sending and responding to WRE after hours through their own will, rather than feeling forced to do so, they may be less likely to experience burnout.

\section{Purpose of Dissertation}

The current dissertation aims to make both a theoretical and practical contribution to the emerging literature on the impact of technology on employee health and well-being by testing a unique model of antecedents and consequences of WRE use after work hours. Several individual, job, and workplace variables will be tested as antecedents of 
WRE use after hours, which takes a novel step towards understanding the influence of more specific factors on employees' decisions to send and read WRE after hours. Research has yet to test variables such as perceptions of others' use, subjective expectations of use, job relevance, and perceived usefulness as antecedents of WRE use after hours, allowing the present study to offer unique insight into the influence of factors specific to the job and the workplace on an employee's after hour WRE use. In addition, examining burnout as an outcome will allow for an exploration of possible negative effects of WRE use after hours. Given that there is a dearth of research on the influence of modern technology on employee well-being, this line of research is necessary during this age of rapid technological advancement.

The examination of voluntariness as a moderator of the relationship between WRE use after hours and burnout also makes a unique contribution to the growing literature in this area. If voluntariness is found to weaken the relationship between WRE use after hours and employee burnout, organizations may wish to take measures to increase levels of job control specific to WRE use after hours by conveying to employees that keeping up with WRE while off the clock is not mandatory, in order to prevent negative outcomes such as burnout. In addition, understanding how social cues and job characteristics influence WRE use will allow organizations and researchers to gain better insight into characteristics of the workplace and/or a job that can influence employees' decisions to engage in WRE use after work hours. The following chapter of the dissertation (Chapter II) contains a detailed literature review of the constructs of interest in the proposed model. Chapter III, the method section, then discusses the sample, procedure, and measures utilized in the study. Chapter IV presents the study results, and 
is followed by Chapter V, the discussion section, containing a summary of findings, interpretation of the results, a discussion of practical implications and societal impact, a summary of limitations, and concluding remarks. 


\section{LITERATURE REVIEW}

Work-related email (WRE) use after work hours, the focal variable in this dissertation, can be defined as sending, reading, or checking emails relating to one's job during nonwork hours (e.g., on the weekends, after the close of business, during sick days, while on vacation). The use of WRE after hours refers to keeping up with emails relating to any kind of job-related tasks. For example, sending emails to clients, responding to emails from supervisors, or checking emails from coworkers all fall into the realm of using WRE after work hours. Chapter II contains a discussion of the status of research related to the use of WRE after work hours, as well as a detailed review of the literature on the various variables being examined as antecedents, consequences, and moderators in the present study.

\section{Work-Related Email Use}

The use of email for work-related communications is a relatively modern phenomenon, being that email was introduced to society fewer than five decades ago. The increase in popularity of its use for work-related purposes is even more recent. Since 2005 , the number of business-related emails sent per person per day has increased from 44 to 122 within a 10-year period. Although research on the effects of keeping up with WRE after work hours is scant, given that WRE use has only more recently seen a spike in popularity, a few researchers have examined predictors of email use and possible outcomes of email overload. In addition, more general work-related technology use, such as technology assisted supplemental work and the use of job-related communication technology after work hours, have been examined. 
A study conducted by Dabbish et al. (2005) sought to examine the characteristics of an email message, the job, and the sender to determine what prompts an employee to take action upon receiving the message. Variables such as message importance, message content, and sender role were measured. Findings suggest that more so than message importance, message content and sender role have a stronger effect on whether individuals replied to email messages received. More specifically, if a message had multiple recipients, employees were less likely to reply to it, and if it requested information or was a social message, employees were more likely to reply to it. The importance rating given to email messages by employees and the relationship that they have with the sender of the message also predicted whether an employee would reply, although the effect was not as strong.

Another study by Dabbish and Kraut (2006) examined the influence of several factors on email strain in a sample of white collar office workers. Variables such as email volume, email management tactics, and email overload (i.e., the perception that one is not able to keep up with his or her work-related email) were measured. More specifically, some of the email message strategies examined were separating messages into folders, restricting the checking of email to specific time periods during the day, and using one's inbox as a "to do" list. Results showed that using a strategy for email management moderated the significantly positive relationship between email volume and feelings of email overload.

A study examining similar variables in a sample of academics was conducted by Jerejian, Reid, and Rees (2013). Interestingly, this study did not find that email management strategies moderated the relationship between email volume and email 
overload. One explanation for this finding may be that in academia, there is an increasing expectation that faculty should be able to be contactable at any time, resulting in a more frequent checking of email throughout the day. In addition, having a tendency to worry was also found to influence email strain, with higher trait worry associated with greater feelings of email overload. This study brings to light the importance of differentiating between workers with clear working hours (e.g., office workers) and those with more ambiguous start and stop times for work (e.g., academics).

Sumecki, Chipulu, and Ojiako (2011) took a different approach to examining employees' perceptions of email importance and use by measuring employees' views of email as a tool critical to their business. Sumecki and colleagues argued that if organizations do not have a clear code for email use, employees are reliant on their own perceptions of the criticality of email use for their business. In their study, factors such as the number of emails received and time management strategies were found to positively predict email overload. Interestingly, perceptions of the criticality of email were found to have negative effects on email overload, suggesting that those who accept email to be a tool critical to the functioning of their business are less likely to experience feelings of stress relating to email.

In addition to examining factors that can influence the use and/or perceptions towards the use of WRE, some studies have examined outcomes of engaging in WRE after hours. One such study conducted by Park and Jex (2011) examined the influence of communication technology use after work hours on the work-family interference in a sample of office workers. Results indicated that relationships between individual factors (i.e., segmentation preference and work-role identification) and psychological work- 
family interference are mediated by the creation of boundaries around communication technology use at work and at home. These findings imply that establishing boundaries around the use of WRE during nonwork hours (e.g., only checking emails during specific times) can help to reduce psychological conflict across work and home domains.

A recent study examining the use of work-related communication technology

after work hours was conducted by Wright et al. (2014). Wright and colleagues examined the influence of work-related communication technology use after regular work hours on outcomes such as employee burnout, work-life conflict, job satisfaction, and turnover intentions in a sample of office workers. Staying connected to the workplace after hours through work-related communication technology was found to be positively related to work-life conflict, which in turn was found to predict employee burnout. In addition, this study found that individuals who had more positive perceptions of the use of communication technology after work hours experienced a lower sense of work-life conflict, suggesting that employees who perceive this type of technology as useful for their job and consider it to be a convenient method of staying connected to the workplace while away from work do not experience as much conflict across work and life domains. Although pieces of the model being proposed in this dissertation have been studied, a holistic process model through which individual, job, and workplace-related factors specific to WRE use after hours lead to employee burnout has not yet been tested. The present study proposes that factors such as telepressure, conscientiousness, job relevance, perceived usefulness, perceptions of others' use of WRE after hours, and subjective expectations of use can influence one's engagement in WRE use after hours, which can then in turn result in emotional exhaustion, cynicism, and a reduced sense of 
personal accomplishment (i.e., components of employee burnout). The current study also proposes that a job control variable specific to WRE use after hours (i.e., voluntariness) can buffer the effect that keeping up with WRE use after hours can have on employee burnout. Figure 2 shows the full model of antecedents, consequences, and moderator variables proposed in this dissertation.

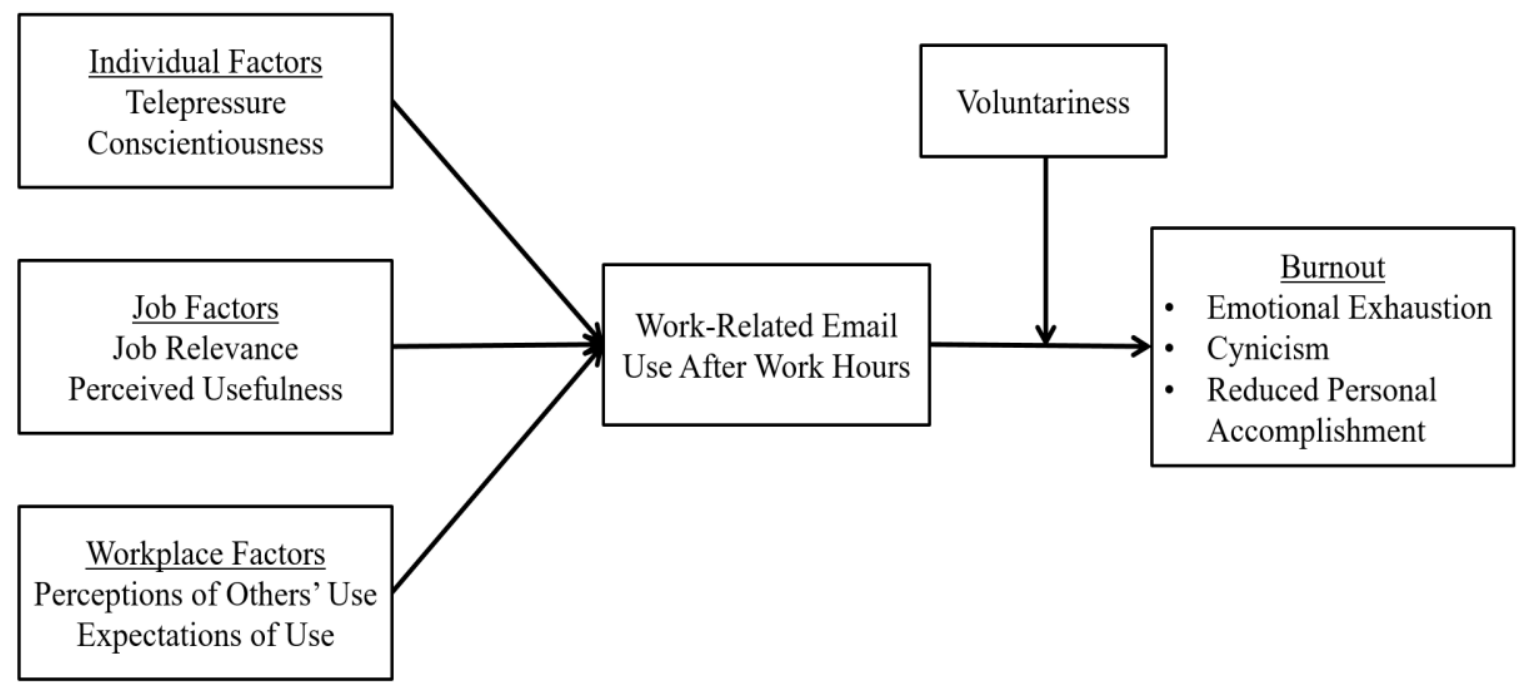

Figure 2. The full model of proposed antecedents, consequences, and moderator variables.

\section{Antecedents of Work-Related Email Use After Hours}

The present dissertation proposes that several factors will influence employees to engage in a particular work-related behavior, which is WRE use after work hours in the present study. The relationship between individuals and their environments is complex, resulting in a need to organize different influential factors into a hierarchy to more thoroughly understand these relationships, interactions between these relationships, and their influence on employees' behavior. Through considering variables at different levels of a hierarchy, a more accurate and holistic examination of the predictors of WRE use 
after hours can be conducted. Therefore, the present study proposes that factors at the individual, job, and workplace level can influence an employee's decision to engage in after hour WRE use.

The ecological model developed by Bronfenbrenner (1977) can serve as a foundation in defining a multi-level framework for individual and environment predictors of employee behavior. The ecological systems theory posits that systems are dynamic, exist at different levels, and are interconnected (Bronfenbrenner, 1977). In other words, no single factor is likely to predict complex human behavior as accurately as a multitude of interactions among factors at different levels. Being that an organization most definitely consists of a series of interconnected systems, an ecological model of the workplace can be useful in examining predictors of complex workplace behavior.

The ecological model was originally created to study human development, and proposes that systems exist on several levels which all interact with one another to influence the development of a child (see Figure 3). At the core is the individual and his or her biological and psychological features. Person-level factors, such as age, gender, individual perceptions, attitudes, and beliefs are all categorized at this level. The microsystem, which is an individual's immediate environment, is the next level in the model. The microsystem layer includes individuals, groups, or institutions that have the most direct effect on an individual, such as family, peers, and schools. The next level, called the mesosystem, includes interactions between elements of the microsystem. For example, relationships between an individual's parents and their schools would fall into this layer of the model. The exosystem, which is directly beyond the mesosystem, contains factors that do not directly influence the individual. Examples of factors that fall 
into this level are community, industry, and media. Finally, the macrosystem relates to cultures and societal influences, including things such as cultural values, societal customs, and national laws (Brofenbrenner, 1977).

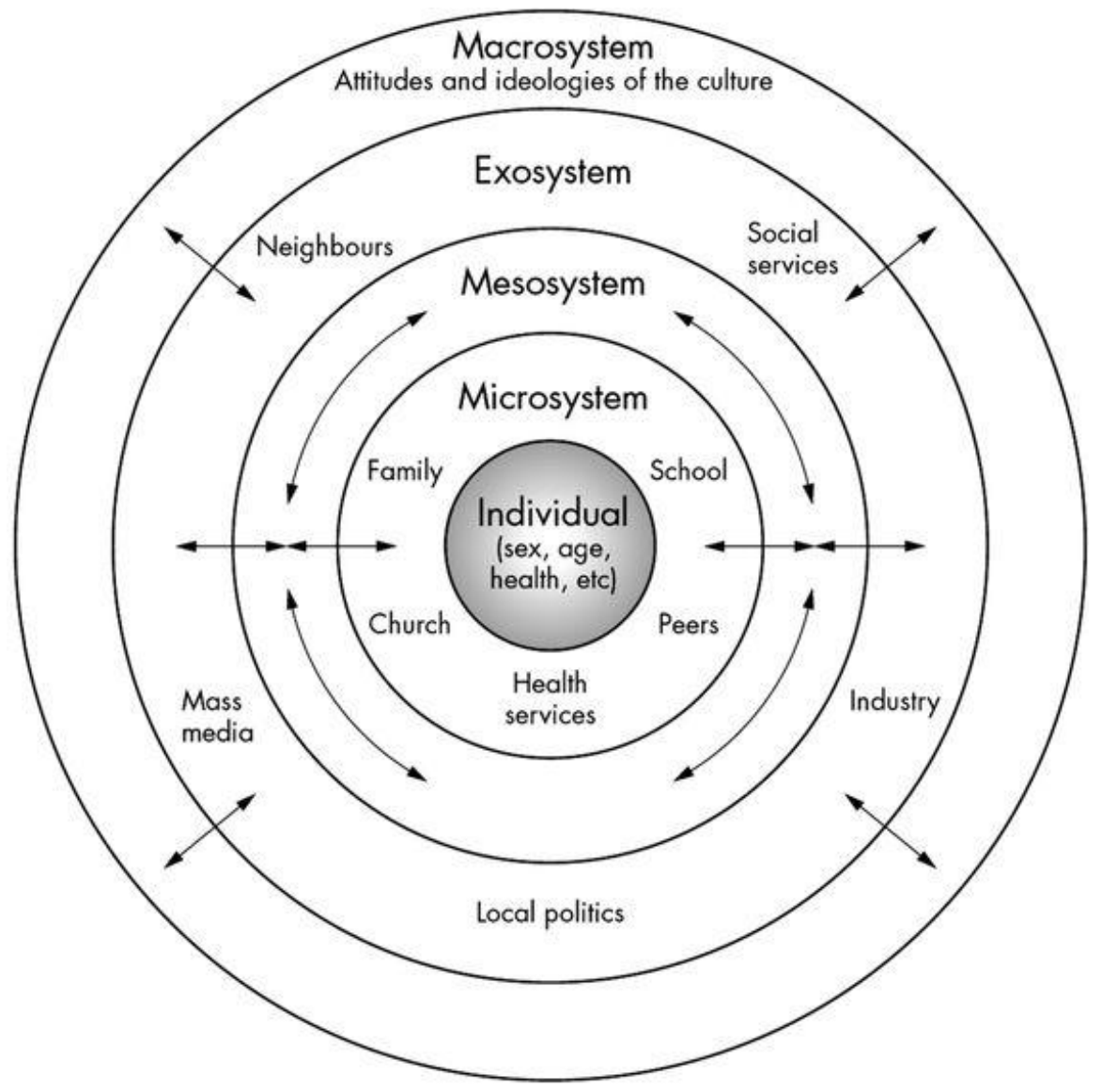

Figure 3. The ecological systems model.

Although first applied to research in human development, the ecological model has since been applied to a variety of contexts. Salazar and Primomo (1994) have adapted Brofenbrenner's model to explain environmental health issues, for example. The ecological model has also been used in organizational research to explain behaviors such 
as workplace bullying (Johnson, 2011) and responses to occupational stress (Salazar \& Beaton, 2000).

Salazar and Beaton's (2000) ecological model of occupational stress proposes four levels of stressors that can result in psychological, physiological, and behavioral stress responses. The first level is the microsystem, which is the immediate environment of a worker. This layer can include factors directly related to the job such as work hours, job control, complexity of work, time pressures, and work overload. The organizational system, which is composed of several microsystems, includes factors such as leadership, manager/supervisor attitudes, and formal and informal policies. The peri-organizational system, consisting of the larger system directly outside of the organization, contains factors such as unemployment rates and community attitudes and perceptions of the organization. Lastly, the extra-organizational system contains cultural factors and customs that may affect an organization, such as societal norms and government regulations.

The present dissertation aims to explore the influence of factors categorized at three different levels on an individual's decision to send, read, and/or check WRE after work hours. Most factors being examined within this model are specific to the use of WRE after hours to allow for a more accurate prediction of this specific and complex behavior. The model being developed and used in this study contains the following three layers of factors:

- Individual factors: Person-level psychological states or personality traits that contribute to the prediction of a particular work-related behavior. In the context of 
the present study, telepressure and conscientiousness are two individual-level factors that are expected to influence one's engagement in WRE use after work hours.

- Job factors: Components of job tasks or the job itself that influence a workrelated behavior. For example, in predicting WRE use after hours, the importance of keeping up with WRE after hours and the degree to which doing so helps an employee perform his or her job better can influence the decision to engage in this behavior.

- Workplace factors: Elements of the workplace or the behavior of representatives of the organization as a whole (e.g., supervisors, managers, leaders, coworkers). Supervisors' or coworkers' engagement in WRE use after hours or supervisors' expectations of employee WRE use can influence workers to keep up with WRE after hours.

It is important to note that the present study will examine individuals' subjective perceptions of factors at these three different levels rather than using more objective measures of these factors, given that individual perceptions are likely to play a more significant role in predicting one's own behavior. Indeed, several researchers take the position that the only way to gain insight into the process through which a stressful workrelated situation (i.e., a stressor) leads to a psychological, physical, or behavior response (i.e., strain) is through measuring individuals' subjective appraisals of stressors (Ganster, 2008; Lazarus, 1991; Perrewe and Zellars, 1999; Spector, 1994). For example, an individual's perception of the importance of WRE use after hours for his or her job can 
be a stronger driver of actual WRE use after hours than a more objective indicator of how important WRE use after hours actually is for the job.

Individual factors. Two person-level factors will be examined as individual-level antecedents in the present study. Telepressure, the first variable of interest, is specific to an individual's psychological connection with the use of work-related communication technology (Barber \& Santuzzi, 2014). Conscientiousness, the second variable being examined at the person-level, is a more general personality trait which has consistently been found to predict organizational citizenship behavior (Chiaburu et al., 2011; Ilies et al., 2009; Organ \& Ryan, 1995), which WRE use after work hours can be considered a form of.

Telepressure. Telepressure can be defined as a psychological state which consists of a having a strong urge to be responsive to others through message-based communication technology, as well as having a preoccupation with responding to workrelated messages quickly. Telepressure has become an increasing concern as the use of email for work-related communication has become more common. Workplace telepressure arises when employees start to view email, which is an asynchronous form of communication, to be similar to synchronous forms of communication. When an employee is asked a question face-to-face (i.e., synchronous communication) an immediate answer is required; however, when an employee receives an email (i.e., asynchronous communication), he or she has some time to respond. In other words, an immediate reply is not necessary in asynchronous communication, and other tasks can be completed between the time the communication is received and the time of response. 
When employees feel high levels of telepressure, they feel an urge to answer asynchronous forms of communication as quickly as what is expected in synchronous forms of communication. Telepressured employees may feel that an immediate response is necessary, and may also feel that they cannot or should not complete any other tasks without responding to a message, resulting in a preoccupation with responding to the message (Barber \& Santuzzi, 2014).

Telepressure is distinct from, but related to, other technology-related constructs such as techno-invasion, technostress, and email overload. Techno-invasion is a general term used to describe the intrusive nature of communication technology in employees' everyday lives. For example, the effects of techno-invasion can be seen in employees who are constantly connected to the workplace through portable communication devices, which can blur the boundaries between their work and nonwork domains. One outcome of techno-invasion may be technostress, which is a psychological state in which an individual is not able to cope with the use of information technology in a healthy manner (Ragu-Nathan, Tarafdar, Ragu-Nathan, \& Tu, 2008). For example, those overwhelmed with receiving work-related emails during nonbusiness hours may cope with this situation by developing a habit to quickly and frequently respond to work-related messages, leading them to feel telepressured. Email overload, which is considered to be employees' perceptions that the quantity of emails they send and receive is more than they can effectively manage (Dabbish \& Kraut, 2006), may result in telepressure. Email overload is distinct from telepressure in that email overload relates to perceptions of the management of the actual amount of email being sent and received while telepressure 
relates to one's urge to respond to these emails quickly. Therefore, telepressure may be a maladaptive way to cope with feelings of email overload.

Telepressure and email overload have been examined in relation to several physical and psychological outcomes. Workplace telepressure was found to predict both physical and cognitive burnout (Baber \& Santizzi, 2014), and email overload has also been found to have a relationship with burnout (Reinke \& Chamorro-Premuzic, 2014). In addition, employees who reported higher telepressure also reported that they were not able to psychologically detach from work, indicating that they do not have enough opportunity after work hours to recover resources lost during the workday (Baber \& Santizzi, 2014).

Sleep quality has also been found to have a relationship with telepressure (Baber \& Santizzi, 2014; Thommes, 2015). However, Baber and Santizzi found that telepressure was not significantly related to sleep duration or consistency. Thommes (2015) found that compared to employees who report not feeling telepressured, those that experience telepressure report a poorer quality of sleep. Baber and Jenkins (2014) suggest that creating boundaries between work and home domains around the use of communication technologies may promote psychological detachment from work, which in turn can improve sleep quality. These studies bring to light the broad impact that email use can have on employee health and well-being.

Taken together, the importance of further examining the role of telepressure in WRE use is apparent, especially in this age of rapid technological advancement. Individuals that feel the urge to respond to message-based communication after work hours and are preoccupied with responding to such messages may be more likely to 
engage in WRE use after work hours. In addition, although telepressure has been found to have a relationship with burnout, WRE use is likely to mediate this relationship. Telepressured employees who succumb to their urges of responding to emails by engaging in WRE use after hours may be more likely to experience burnout.

Hypothesis 1: Telepressure will be positively related to WRE use after work hours.

Conscientiousness. One of the most comprehensive methods of measuring personality is through assessing the Big Five personality characteristics, which consist of extraversion, conscientiousness, openness to experience, agreeableness, and neuroticism. Individuals high in extraversion tend to be bold, energetic, action-oriented, and assertive. Conscientious individuals are characterized as responsible, dependable, and practical. Individuals that display openness to experience tend to be curious, imaginative, and intelligent. Agreeable individuals are cooperative, unselfish, and trustful. Finally, individuals high in neuroticism are often characterized as emotionally unstable, anxious, easily embarrassed, and insecure (Goldberg, 1992).

Conscientiousness, in particular, has been found to be one of the most consistent predictors of organizational citizenship behavior (Chiaburu et al., 2011; Ilies et al., 2009; Organ \& Ryan, 1995), which can be defined as an act that goes beyond the formal requirements of a job (Organ, 1988). For example, volunteering for extra work tasks, helping coworkers who need additional help, and making suggestions for improving work conditions can all be considered citizenship behaviors. Keeping up with WRE after hours can be considered an organizational citizenship behavior, given that reading and sending work-related messages after work hours are acts that are not formally required by a job. 
Since administrative assistants and office workers (i.e., the sample being examined in the present study) usually have clear start and stop times for their work, any work-related tasks, including sending, reading, or responding to WRE after hours, may be considered organizational citizenship behavior.

The present dissertation will be examining whether individuals high in the trait of conscientiousness are more likely to engage in WRE use after work hours. Given that conscientious individuals are characterized as achievement-oriented, dependable, and diligent (Goldberg, 1992), those high in this personality trait may be more likely to keep up with WRE after hours. Conscientious individuals may remain diligent and responsive to WRE emails after hours in order to achieve their work-related goals. For example, if highly conscientious employees receive an email from a supervisor after work hours, they may be more likely to reply because of their responsive and reliable nature (Barber \& Santuzzi, 2014). In addition, conscientious employees who are striving towards work goals such as gaining a promotion, receiving a recommendation from a supervisor, or gaining rewards or recognition, may be more likely to engage in WRE after hours if they consider it to be helpful in achieving their goal. Indeed, conscientiousness was found to have significant positive relationship with telepressure in a study by Barber and Santuzzi (2014).

Hypothesis 2: Conscientiousness will be positively related to WRE use after work hours.

Job factors. The technology acceptance model (TAM), one of the most widely used models of technology usage and acceptance, posits that an individual's intention to use a technological system in the workplace is derived from factors such as the perceived 
usefulness of the technology in enhancing job performance and perceived ease of using the technology (Davis, 1989; Davis, Bagozzi, \& Warshaw, 1989). In 2000, Venkatesh and Davis extended the TAM to include the influence of external variables on individuals' perceptions of the usefulness of a system. The extended model, called the TAM2, proposes that variables such as subjective norms and job relevance can influence how useful individuals consider a particular technology to be for their job. Several studies have found support for the TAM and TAM2 (Adams, Nelson, \& Todd, 1992; Davis, 1989; Hendrickson, Massey, \& Cronan, 1993; Subramanian, 1994; Szajna, 1994; Venkatesh \& Davis, 2000).

Although the TAM is commonly used to explain employees' use and acceptance of new technological system introduced to the workplace, several variables introduced within this model can be useful in explaining an individual's intention to or tendency to use technology for work-related purposes outside of the workplace. Indeed, a multitude of recent research has adapted and/or modified the TAM to be used for studying various phenomena such as engagement in e-learning (Abdullah \& Ward, 2016), use of cloudcomputing (Sabi, Uzoka, Faith-Michael, Langmia, \& Njeh, 2016), and mobile instant messaging (Bere \& Rambe, 2016). Similarly, the present study aims to examine two constructs introduced within the TAM in relation to WRE use after work hours, and proposes that the degree to which after hour WRE use is relevant to one's job and the extent to which an individual considers WRE use after hours to be useful in enhancing his or her job performance will influence their decision to keep up with WRE after work hours. 
Job relevance. Within the TAM2, job relevance is defined as the degree to which employees consider a particular technological system to be applicable to their jobs. The TAM2 proposes that job relevance predicts perceived usefulness, suggesting that perceptions of how relevant a system is to complete work tasks influences the degree to which individuals consider a system to be useful for their job performance (Venkatesh \& Davis, 2000). Kieras and Polson (1985) suggest that system users hold unique knowledge about the tasks that they need to complete along with possessing greater insight into their own job goals. Therefore, employees themselves are best able to gauge how well a system can be used to complete required work. Employees perceptions of job relevance may be more important to assess than job-determined importance (Leonard-Barton \& Deschamps, 1988) because regardless of how important keeping up with WRE after work hours actually is to a job, individuals' own perceptions of importance are likely to be stronger drivers of their behavior than more objective indicators of importance. Indeed, Venkatesh and Davis (2000) found that employees' perceptions of job relevance had a significant positive effect on perceptions of the usefulness of a system in a series of studies.

In the context of the present study, job relevance will be defined as the degree to which individuals consider WRE use after hours to be important and applicable to their job. The model proposed in this dissertation posits that job relevance is likely to have a direct effect on WRE use after hours, which slightly differs from the indirect effect proposed within the original TAM2. Even if individuals do not find the use of WRE after work hours to be important for their own job performance, considering the use of WRE after hours to be important to their job as a whole may play a role in whether they decide 
to engage in the behavior. The importance of job relevance is supported by the finding that the "business criticality" of email use does in fact influence feelings of email overload (Sumecki et al., 2011). Therefore, if individuals consider the use of WRE after work hours to be critical to the effective functioning of their business and consider it to be greatly relevant to their job, they may be more likely to keep up with WRE after work hours.

Hypothesis 3: Job relevance will be positively related to WRE use after work hours.

Perceived usefulness. Perceived usefulness can be considered the degree to which an individual feels that the use a certain technological system will enhance his or her job performance. The TAM2 posits that external variables such as system characteristics and system training can influence perceptions of usefulness, which in turn results in the intention to use a particular system. Venkatesh and Davis (2000) found support for the influence of external factors such as subjective workplace norms, image (i.e., the degree to which individuals consider the use a system to increase their status at work), and results demonstrability (i.e., the degree to which outputs from the use of a system are tangible) on the perceived usefulness of a system. In addition, perceptions of job relevance were found to have a significant positive effect on perceived usefulness, and perceived usefulness mediated the relationship between job relevance and intention to use a particular technology.

The present study defines perceived usefulness as the degree to which employees consider WRE use after work hours to aid in their overall job performance and/or productivity. It is proposed that if employees feel that keeping up with WRE after hours 
makes them better performers, increases their productivity, and/or aids in completing job tasks more effectively, they are more likely to engage in the behavior. Indeed, research supports the notion that employees engage in organizational citizenship behaviors if they believe that doing so can help them gain rewards or recognition (Ariani, 2012). In addition, a multitude of research supports the link between engaging in citizenship behaviors and receiving more positive performance ratings and greater rewards (Podsakoff, Whiting, Podsakoff, \& Blume, 2009; Podsakoff, Whiting, Podsakoff, \& Mishra, 2010), even though organizational citizenship behaviors are not, by definition, formally rewarded. Since WRE use after hours can be considered an organizational citizenship behavior, it is likely that those individuals who consider engaging in this behavior to increase their job performance or productivity will be more likely to keep up with WRE after hours.

Hypothesis 4: Perceived usefulness will be positively related to WRE use after work hours.

Workplace factors. If there are no formal organizational policies on the use of WRE after hours, such as Volkswagen's policy mentioned in the previous chapter, employees are likely to depend upon social norms to determine whether they should be checking, responding to, and sending WRE during nonwork hours. Even if there are formal organizational policies, employees may be more likely to take cues from their peers' behavior, or follow what they feel is expected of them, especially when these policies are not or cannot be strictly enforced. A myriad of research on social norms and social influence suggests that individuals adapt to their social environment through changing their own behavior to match the observed behavior of others (Bandura, 1977; 
Brauer \& Chaurand, 2010; Cialdini \& Goldstein, 2004; Fishbein \& Ajzen, 1975; Lapinski \& Rimal, 2005).

Social norms can be defined as shared expectations or individual perceptions of behavior that are acceptable in society or in a particular group (Jackson, 1965; Lapinski \& Rimal, 2005). Social norms guide behavior by indicating to individuals what behaviors are appropriate in particular situations (Haralambos \& Holborn, 2000). Norms can be collective, meaning that they are defined at the group-level in a particular social system (e.g., a company, team, or society). Collective norms indicate what individuals should and should not do, defined as prescriptive and proscriptive norms, respectively (Lapinski \& Rimal, 2005). For example, giving a handshake when meeting someone in a professional setting can be considered a prescriptive norm in the United States, while smoking a cigarette during a work-related meeting could be considered a proscriptive norm. Collective norms can differ across societies and groups, and over time. Arguably, individual-level perceptions of collective norms, termed perceived norms, are stronger drivers of individual behavior than collective norms themselves. Collective norms can be thought of as unwritten laws that are rarely stated explicitly. Therefore, not all individuals may correctly interpret collective norms. Perceived norms exist on a psychological-level, and involve a process through which individuals in a social system interpret what should and should not be done in particular situations (Lapinski \& Rimal, 2005).

Social norms can also be conceptualized as descriptive or injunctive norms. Descriptive norms are considered to be individuals' perceptions of what types behaviors are typically performed in a group. Descriptive norms are usually formed through a non- 
judgmental observation of the behavior of others in one's social group, and reaching a conclusion about what most people do in certain situations (Cialdini, Kallgren, \& Reno, 1991). For example, if employees see their coworkers behaving safely on the job, they may perceive safe behavior to be a descriptive norm.

Injunctive norms are perceptions of what types of behaviors individuals in one's social system consider to be appropriate or expected (Cialdini et al., 1991). For example, if employees think that their coworkers consider taking shortcuts when completing tasks to be acceptable behavior, they may perceive taking shortcuts to be an injunctive norm. One way in which injunctive norms are formed are though individuals' subjective norms, defined as the degree to which they feel that important others want (or do not want) them to behave in a particular way (Rivis \& Sheeran, 2003). For example, working overtime would be considered a subjective norm if an employee perceives a supervisor as consistently pressuring him or her to work late. In essence, descriptive norms illustrate what is commonly done within a group of people and injunctive norms depict what should be done (Lapinski \& Rimal, 2005). The present dissertation assesses the influence of employees' perceptions of both descriptive and injunctive norms on their WRE use after hours. The extent to which supervisors and coworkers keep up with up WRE during nonwork time can influence an employee's perceptions of descriptive norms within their workplace, and subjective expectations of WRE use after hours can be considered injunctive norms.

Perceptions of supervisors' and coworkers' use. Deutsch and Gerard (1955) suggest that individual members of a group have the tendency to observe other members of the group to mold their own behavior (i.e., informational influence). The degree to 
which employees perceive their supervisors and/or coworkers to use WRE after hours can act as an indicator of descriptive norms. If employees observe their coworkers sending WRE after hours, or receive WRE during nonwork hours from supervisors, they may consider it to be a typical workplace behavior. In addition, rather than the degree to which supervisors and coworkers actually keep up with WRE after hours, employees' perceptions of supervisors' and coworkers' use may influence employees' behavior more so than actual use. Receiving a late-night email from a supervisor may result in employees perceiving their supervisors as always active on WRE, although this may not necessarily be the case. Employees' perceptions that others are keeping up with the WRE can result in an increase in an employee's own WRE use after work hours.

Hypothesis 5: Employees' perceptions of supervisors' and coworkers' use of WRE after hours will be positively related to their own WRE use after work hours.

Subjective expectation of use. The degree to which employees feel that important others (e.g., supervisors, coworkers, etc.) expect them to send or respond to WRE after hours is considered their subjective expectation of use. Employees' subjective expectations of use can influence their engagement in WRE after hours by acting as an injunctive norm. If employees feel that their supervisors or important coworkers expect them to read or respond to WRE even while "off the clock," they may perceive keeping up with WRE after hours as something that should be done, leading them to engage in the behavior more frequently.

Hypothesis 6: Employees' subjective expectations of keeping up with their WRE after hours will be positively related to their WRE use after work hours. 


\section{Consequences of Work-Related Email Use After Hours}

The present dissertation proposes that emotional exhaustion, cynicism, and a reduced sense of professional accomplishment (i.e., the three components of employee burnout) can result from consistent WRE use after hours. As previously discussed, WRE serves as a psychological link to the workplace while at home, which may cause employees to feel that they are "on call" during nonwork hours. Employees may therefore not be able to sufficiently recuperate their mental and physical energy expended during the work day, resulting in burnout. It is also proposed that a job control variable specific to WRE use after hours (i.e., voluntariness) will influence the relationship between WRE use after work and burnout, such that employees who experience higher voluntariness will be less prone to experiencing burnout.

Burnout. Burnout can be described as a distressed psychological state characterized by depleted mental energy, cynical feelings towards work, and a lowered sense of personal accomplishment (Maslach, 1998). Although burnout has been defined in various ways, with some researchers considering it to be unidimensional construct (Freudenberger \& Richelson, 1980; Pines \& Aronson, 1988; Shirom, 1989) and others as a multifaceted construct (Demerouti, 1999; Maslach, Schaufei \& Leiter, 2001) The most popular view of burnout, however, is as a three-dimensional construct consisting of emotional exhaustion, cynicism, and reduced personal accomplishment. Emotional exhaustion can be defined as the depletion of mental energy. When individuals lack the resources to meet high job demands, they may experience feelings of overexertion, which can lead them to feel unable to recover from this state. Cynicism refers to individuals distancing themselves from their work, which can lead them to develop negative feelings 
towards work itself. Reduced personal accomplishment refers to feelings about a lack of accomplishment and competence, along with feelings of inefficacy (Maslach et al., 2001).

Early researchers proposed that burnout is most prevalent in human service professions, such as healthcare, social work, and teaching (Jackson, Schwab, \& Schuler, 1986; Maslach \& Kackson, 1986), because of the emotional demands of such jobs and the high stress associated with them (Ruotsalainen, Verbeek, Mariné, Serra, 2014). However, researchers have posited that there is no rationale for burnout occurring solely in human service occupations (Demerouti et al., 2001), with a multitude of research in the past decade supporting the idea that employee burnout can be experienced by individuals in any profession (Baker, Demerouti \& Schaufeli, 2002; Demerouti et al., 2001; Leiter \& Schaufeli, 1996). For example, Demerouti et al. (2001) conducted a study examining burnout in several industries, and found similar patterns of relationships between job demands and burnout across professions. The sample consisted of individuals working in human services (i.e., teachers and nurses), industry (i.e., assembly line workers, photo print developers, and control room operators), and transport (i.e., air traffic controllers). They found that job demands, such as physical workload, time pressures, physical environment, and shift work, all had significant relationships with both self-reported and observed burnout across all three occupational categories.

The emotional exhaustion facet of burnout has often been considered as the core component of the construct, with some researchers questioning the necessity of conceptualizing burnout as a three dimensional construct (see Demerouti et al., 2001; Halbesleben \& Bowler, 2007; Shirom, 2003). However, Maslach and colleagues (2001) 
argue that the emotional exhaustion component of burnout is not sufficient to capture the entirety of the construct, and that burnout should be extended to capture possible responses to emotional exhaustion. For example, being emotionally exhausted can cause employees to distance themselves from their work, both mentally and emotionally, which causes them to depersonalize themselves from their role at work. In other words, cynicism may be a coping strategy for feelings of emotional exhaustion (Maslach, 1993).

The relationship that reduced personal accomplishment has with emotional exhaustion and cynicism is not as clear as the relationship between the other two dimensions (Maslach et al., 2001). Indeed, personal accomplishment has often been found to have the weakest intercorrelations with the other two components of burnout (Lee \& Ashforth, 1996). However, when emotionally exhausted employees feel that their performance or productivity is not as high as it was in the past (i.e., when they did not feel emotionally exhausted), a reduced sense of personal accomplishment may result. Weak intercorrelations between reduced personal accomplishment and the other two facets of burnout may be seen because 1) this outcome may not always be experienced, or 2) several other workplace factors and/or individual differences can influence feelings of personal accomplishment.

Burnout has been found to have relationships with several work-related stressors and strains. Burnout, especially the emotional exhaustion component, has had consistent relationships with work demands (Bakker, Demerouti, \& Verbeke, 2004; Hockey, 1993). Lee and Ashforth (1996) conducted a meta-analysis of the relationships between all three dimensions of burnout and several job stressors, support variables, job enhancement opportunities, reinforcement contingencies, and behavioral and attitudinal outcomes. 
While emotional exhaustion and cynicism were found to be related to a few variables in all of these five job demand and resource categories, personal accomplishment was only found to have relationships with a few support variables, reinforcement contingencies, and behavioral and attitudinal outcomes. In a review of the literature on burnout, Corders and Dougherty (1993) conclude that employees experiencing burnout are more likely to be dissatisfied with their work, display poor performance, are more likely to leave their organization, and experience various physical and psychological health symptoms. For example, research has found that burnout is related to a range of physical conditions such as a poor appetite, chest pains, back pains, headaches (Beehr, Bowling, \& Bennett, 2010; Burke \& Deszca, 1986), and anxiety (Maslach, 1982).

The model proposed in this dissertation posits that emotional exhaustion, cynicism, and a reduced sense of personal accomplishment will result from WRE use after hours. Work-related email use after hours may lead to a self-assigned increase in workload, since engaging in this behavior is not formally required by an organization, and heavy workloads have consistently been found to be predictors of burnout (see Cordes \& Dougherty, 1993; Lee \& Ashforth, 1996; Maslach \& Leiter, 2008). In addition, WRE use after work can drastically reduce the number of opportunities for an employee to psychologically detach from work and replenish lost resources. Indeed, WRE use after work has been found to have a negative relationship with psychological detachment (Park, Fritz, \& Jex, 2011). Therefore, it is predicted that using WRE after hours can result in emotional exhaustion, given that employees may not have adequate time to recover lost resources during the work day, resulting in employees feeling cynical about their job and developing negative feelings towards their work. Employees may then develop a 
reduced sense of personal accomplishment if they sense a decrease in their productivity or performance due to feeling emotionally exhausted.

Hypothesis 7a: WRE use after hours will be positively related to emotional exhaustion.

Hypothesis 7b: WRE use after hours will be positively related to cynicism.

Hypothesis 7c: WRE use after hours will be positively related to reduced personal accomplishment.

\section{Voluntariness as a Moderator}

The extent to which employees perceive the use of a particular technology as nonmandatory is termed "voluntariness" (Hartwick \& Barki, 1994). Although this construct was originally developed to assess one's control over the use of a new technology introduced into the workplace, voluntariness can also be used to describe the sense of control that individuals feel over the use of WRE after work. If individuals feel that keeping up with WRE after hours is not mandatory, and that they are writing, responding to, and reading WRE after hours based on their own free will rather than being forced to do so, they may be less likely to experience burnout.

The relationships between WRE use after hours, voluntariness, and burnout can be understood through the job demands-resources model, which suggests that strain results from an imbalance between the work demands being placed on employees and the resources that they possess for meeting and/or coping with those demands (Demerouti et al., 2001). The job demands-resources model follows the job demands-control model (Karasek, 1979), which suggests that work demands, such as heavy workloads, can result 
in stress or low work motivation if paired with low levels of job control, defined as the degree to which employees feel that they have influence over their work environment (Ganster, 1989), such their roles, tasks, and quality of work (Dwyer \& Ganster, 1991). Job control has been examined in relation to several psychological and behavioral factors, such as job satisfaction (Bond \& Bunce, 2003) and work performance (Bond \& Flaxman, 2006). Voluntariness can be considered a specific form of job control, given that it captures the decision latitude an individual possesses over using a technology.

The job demands-resources model expands upon the job demand-control model by proposing more inclusive definitions for job demands, and categorizing job control as a job resource. According to this model, job demands can include any organizational, social, physical, or psychological aspect of the job that requires sustained physical and/or psychological effort from an employee. In addition, within this model, job control is conceptualized as a type of job resource, which is any organizational, social, physical, or psychological aspect of a job that does any of the following: 1) helps to achieve work goals; 2) lowers job demands and their physiological and psychological costs; or 3) encourages personal growth (Demerouti et al., 2001). Frese and Fay (2001) consider job control to be an environmental support that increases employees' personal initiatives. In addition, the job demands-resources model examines both positive and negative outcomes of the interaction between job demands and resources. For example, high job demands and low job resources may result in employee burnout; however, high job demands and high job resources can result in increased employee engagement (Schaufeli, Bakker, \& Van Rhenen, 2009; see Figure 4). 


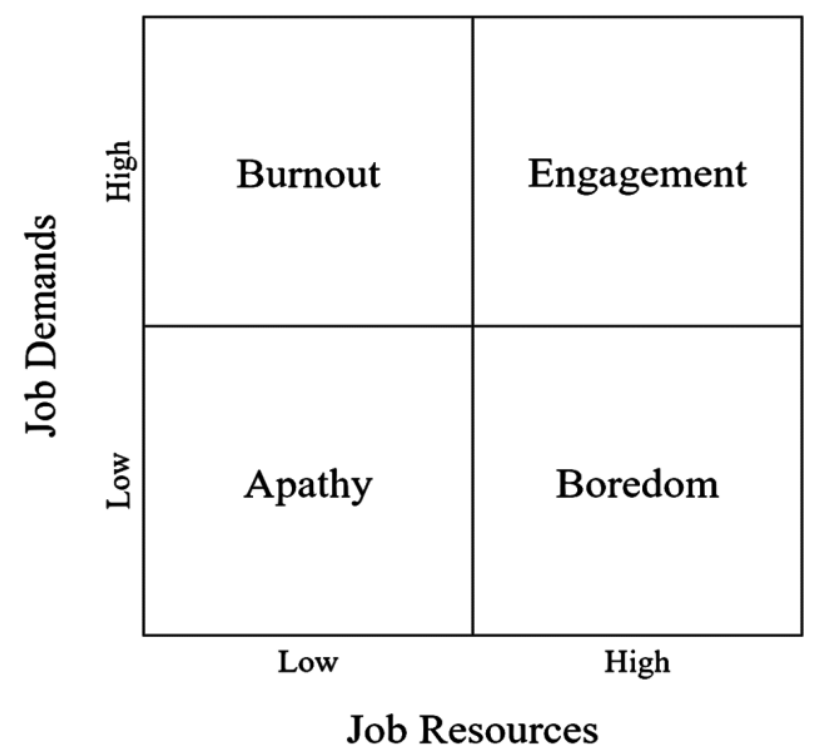

Figure 4. Outcomes of interactions between job demands and job resources.

Employee burnout is arguably the most studied negative outcome of the interaction between job demands and job resources (see Bakker, Demerouti, Taris, Schaufeli, \& Schreurs, 2003; Demerouti et al., 2001; Schaufeli et al., 2009). In addition to the definition previously provided, burnout can also be described as a state in which the resources required to meet the demands of a job exceed the available resources possessed by an individual (Demerouti et al., 2001). In essence, if individuals do not have enough job resources to meet and/or cope with heavy job demands, they can experience emotional exhaustion, cynicism, and reduced personal accomplishment. Consistent negative relationships have also been found between burnout and job control (Fernet et al., 2004; Corders \& Dougherty, 1993).

Bakker, Demerouti, and Euwema (2005) conducted a study in which they examined the interaction of high job demands and low job resources on employees' burnout in the education sector. They found that individuals possessing job resources 
such as autonomy, feedback, and social support were less likely to experience burnout, even under heavy work demands such as work overload, emotional job demands, and physical job demands. Autonomy, which is a more specific form of job control relating to the degree of freedom one has in deciding what type of work is done and how it is completed (Spector, 1986), was found to have the strongest buffering effect on the relationships between the job demands and burnout.

Bakker and Demerouti (2007) examined work demands, job resources, and the three burnout dimensions. Results of their study suggest that when job resources are high, the relationship between job demands and dimensions of burnout are weakened. More specifically, autonomy was again found to have the strongest buffering effect on the relationships between job demands and the exhaustion and cynicism components of burnout. Taken together, these studies support the notion that job control can help to alleviate or prevent burnout symptoms from being experienced in situations of heavy work demands.

The present dissertation proposes that keeping up with WRE after work hours can act as a job demand because it requires sustained psychological effort from an employee to stay mentally connected to the workplace. This psychological effort is not only spent during work hours, but is also sustained after work hours, which is a time usually reserved for psychologically detaching from work. Indeed, psychological detachment, defined as a state in which one mentally disconnects from his or her job and job-related tasks while away from work (Sonnentag, 2011), has consistently been found to have a negative relationship with burnout (Etzion, Eden, \& Lapidot, 1998; Sonnentag, Binnewies, \& Mojza, 2010; Sonnentag, Kuttler, \& Fritz, 2010). Therefore, if employees 
engage in sustained WRE use after hours, it is hypothesized that they are more likely to experience burnout symptoms, since keeping up with WRE after hours can serve as a mental link to work and job-related tasks. However, if employees experience high voluntariness, which can be considered a job resource, the effect that WRE use after hours has on burnout may be weakened, since employees have control over when and in what capacity they keep up with their WRE after hours.

Similar to the multitude of findings that job control buffers the relationship between job demands and burnout (Bakker et al., 2005; Bakker \& Demerouti, 2007; Xanthopoulou, Bakker, Demerouti, \& Schaufeli, 2007), it is hypothesized that voluntariness moderates the relationship between WRE use after hours and the three dimensions of burnout.

Hypothesis 8: Voluntariness will moderate the relationship between WRE use after hours and a) emotional exhaustion, b) cynicism, and c) reduced personal accomplishment, such that higher voluntariness will weaken these relationships.

\section{The Overall Model}

The overall model being tested in this study proposes the process through which individual, job, and workplace factors influence WRE use after hours, and how this behavior results in emotional exhaustion, cynicism, and a reduced sense of personal accomplishment, which are the three components of employee burnout. In addition, the influence of voluntariness, a form of control specific to the use of WRE after hours, on the relationship between WRE use and burnout is also tested within this process model (see Figure 2). 


\section{METHOD}

\section{Participants}

One hundred and thirty-one administrative assistants and office employees from five large public universities in the southeastern United States participated in this study. To qualify for participation, employees must have been a salaried university employee working in an office or administrative position. The majority of employees were female $(86.3 \%)$, with an average age of $35.1(S D=10.1)$. Most participants reported being married (39.7\%) or single (31.3\%). Participants worked an average of 39.8 hours per week $(S D=5.0)$, and most reported earning a salary between $\$ 30,000$ to $\$ 50,000$ per year $(63.3 \%)$. On average, employees reported an organizational tenure of 6.3 years $(S D=5.0)$ and a job tenure of 3.3 years $(S D=3.3)$.

\section{Measures}

The following measures were developed into an online survey using Qualtrics Research Suite. The full survey can be found in the Appendix.

Work-related email use after work hours. The use of WRE after hours was measured through a four-item scale developed for the present study $(\alpha=.97)$. Participants were asked to indicate the extent to which they agreed with statements such as "I tend to check my work-related emails after work hours" and "I tend to send work-related emails after work hours" on a five-point Likert scale, ranging from "strongly disagree" to “strongly agree." Higher scores on this measure indicate greater WRE use after work hours. 
Perceptions of others' use. To measure participants' perceptions of descriptive norms in their workgroup, they were asked to indicate how much they agreed with statements such as "My supervisor reads his/her work emails after work hours" and "My coworkers reply to work-related emails after work hours" on a five-point Likert scale, ranging from "strongly disagree" to "strongly agree." The measure had a total of eight items, with four assessing perceptions of supervisors' use and the other four assessing perceptions of coworkers' use. The full eight-item measure had a Cronbach's alpha of .91 , with the supervisors' use and coworkers' use subscales correlated at .79 . High scores indicate that employees perceive their supervisors and coworkers using WRE after hours to a greater extent.

Subjective expectations of use. Perceptions of injunctive norms were measured by assessing employees' subjective expectations of WRE use after hours using a modified version of a two-item measure developed by Venkatesh and Davis $(2000 ; \alpha=$ .89). Since the measure was originally created in relation to the acceptance of new technology inside of the workplace, items were modified to reflect the use of WRE after hours. For example, the item "People who are important to me think I should use the system" was modified to "People who are important to me think I should keep up with work-related email after work hours." Responses were measured on a five-point Likert scale, ranging from "strongly disagree" to "strongly agree," with higher scores indicating that participants perceive a greater expectation to keep up with WRE after work.

Perceived usefulness. A modified version of a four-item scale developed by Venkatesh and Davis $(2000 ; \alpha=.97)$ was used to assess the perceived usefulness of using WRE after work hours. Example items are "Keeping up with work-related email after 
work hours increases my productivity," and "Keeping up with work-related email after work hours improves my performance in my job." Participants were asked to respond on a five-point Likert scale, ranging from "strongly disagree" to "strongly agree," with higher scores indicating greater perceptions of usefulness.

Job relevance. The job relevance of WRE use after hours was measured using a modified version of a two-item scale developed by Venkatesh and Davis $(2000 ; \alpha=.92)$. An example item in this measure is: "In my job, keeping up with work-related email after work hours is important." Participants were asked to indicate their agreement with each item on a five-point Likert scale, ranging from "strongly disagree" to "strongly agree." Higher scores on this measure indicate that participants perceive the keeping up with WRE use after hours to have more job relevance.

Telepressure. A five-item measure developed by Barber and Santuzzi $(2014 ; \alpha=$ .85 ) will be used to measure workplace telepressure. Items were modified to specifically reflect sending and receiving WRE. For example, items such as "It's hard for me to focus on other things when I receive a work-related email message" measured preoccupation with responding to emails and "It is difficult for me to resist responding to a work-related email message right away" measure the urge to respond to emails. Participants were asked to respond on a five-point Likert scale, ranging from "strongly disagree" to "strongly agree," with higher scores indicating more telepressure.

Conscientiousness. A four-item measure from the Mini International Personality Item Pool (Donnellan, Oswald, Baird, \& Lucas, 2006; $\alpha=.55$ ) was used to measure conscientiousness. Participants were asked to indicate how accurately statements such as "Often forget to put things back in their proper place" and "Like order" describe them, 
using a five-point scale ranging from "very inaccurate" to "very accurate." Higher scores indicate higher conscientiousness.

Burnout. The Maslach Burnout Inventory - General Survey (MBI-GS; Schaufeli, Leiter, Maslach, \& Jackson, 1996) was used to measure the three dimensions of employee burnout. The 16-item measure consisted of three subscales assessing emotional exhaustion $(\alpha=.90)$, cynicism $(\alpha=.86)$, and personal accomplishment $(\alpha=.70)$. An example item within the emotional exhaustion subscale is "I feel emotionally drained from my work." Participants were asked to respond on a seven-point frequency scale ranging from "never" to "every day." Higher scores on the emotional exhaustion and cynicism subscales indicate greater burnout, while lower scores on the professional accomplishment subscale is an indicator of greater burnout. Note that items on the professional accomplishment subscale were reversed scored to align with the emotional exhaustion and cynicism subscales.

Voluntariness. A modified version of a three-item measure developed by Venkatesh and Davis $(2000 ; \alpha=.79)$ was used to measure voluntariness. The measure was developed to assess the voluntariness of the use of technology introduced in the workplace; therefore, items were modified to reflect the use of WRE after work. For example, the item "My supervisor does not require me to use the system" will be modified to "My supervisor does not require me to keep up with work-related email after work hours." Participants were asked to respond on a five-point Likert scale, ranging from "strongly disagree" to "strongly agree," with higher scores indicating the views of WRE after work as voluntarily. 
Demographic variables. Measures of several variables to identify the demographic characteristics of the sample were administered. In addition to commonly measured demographic variables such as age, gender, and tenure, variables relating to job status, family responsibilities, and accessibility of WRE were assessed.

Job status and responsibilities. The frequency at which employees keep up with WRE after hours may depend on their job status at work. Participants were asked to indicate which of the following jobs they most closely identified with: administrative assistant, senior administrative assistant, coordinator of administrator services, office assistant, office associate, office coordinator, office manager, or office specialist. These eight categories are common job titles for administrative workers in universities. Participants were also asked to provide their salary range. In addition, employees were asked to indicate the number of people they supervise at work, and the number of supervisors they have. Lastly, employees were asked to indicate whether their office normally allowed them to work from home.

Family responsibilities. Individuals with caregiver roles or greater responsibilities for household tasks at home may be more likely to detach from work after hours in order to meet those responsibilities. Therefore, participants were asked about their marital status, number of children, and whether they are in any sort of caregiver role (e.g., for their parents or siblings). Employees were also asked to indicate the percentage of daily household tasks, chores, and/or caregiver duties that they are responsible for, and to what extent their family members or friends aid them with these responsibilities.

Accessibility of WRE. Those individuals who connect their WRE to their smartphone or other portable electronic devices may be more likely to keep up with their 
WRE after hours, since doing so allows employees to have access to their WRE from anywhere at any time. In addition, individuals who use their WRE for personal purposes may check their WRE more frequently, since they may see WRE after hours if checking their email account for personal communications during nonwork hours. Coming across WRE after hours may tempt individuals to check, read, or respond to these emails. Therefore, participants were asked to indicate whether they have their WRE connected to their smartphones and if they use their WRE account for personal purposes as well.

\section{Procedure}

Participants were recruited through email communications. Emails containing a description of the study, criteria to participate, the researcher's contact information, and a link to the online survey were sent to office and administrative workers at five public universities in the southeastern United States. Potential participants were identified through a public database containing university employees' names, job titles, fulltime status, and salaries. Those individuals with the job title of administrative assistant, senior administrative assistant, coordinator of administrator services, office assistant, office associate, office coordinator, office manager, or office specialist were sent recruitment emails $(\mathrm{N}=1771)$. Potential participants were also asked to pass along information about the study to coworkers that fell within the inclusion criteria. To participate in the study, individuals were asked to visit a web link that connected them to an online survey of the measures described in the previous section.

A total of 196 surveys were returned. Employees who did not complete at least the measures of WRE use after hours were removed from the dataset. To address 
inattentive responding, five attention check questions (e.g., "Please select slightly disagree") were inserted at random points throughout the survey. Participants who did not respond appropriately to at least four $(80 \%)$ of these items were removed from further analyses (Behrend, Sharek, Meade, \& Wiebe, 2011). This data cleaning procedure resulted in a final sample size of 131 . One hundred and twenty-two of these participants completed $100 \%$ of the survey, while the remaining nine participants completed $31 \%$ to $59 \%$ of the survey. 


\section{RESULTS}

To assess the threat of common method bias, Harman's one-factor test was conducted using all study items. Eleven factors were cumulatively found to explain $77.22 \%$ of variance, and the largest factor was found to explain $23.26 \%$. Since no one factor was found to explain a majority of variance, there was little evidence for common method bias.

Hypotheses 1 through 6 proposed positive relationships between WRE use after hours and several individual (i.e., telepressure and conscientiousness), job (i.e., job relevance and perceived usefulness), and workplace factors (i.e., perceptions of others' use and subjective expectations of use). WRE use after hours was found to have a significant positive relationship with telepressure $(r=.27)$, job relevance $(r=.75)$, perceived usefulness $(r=.78)$, perceptions of others' use $(r=.32)$, and subjective expectations of use $(r=.46)$. Hypotheses $1,3,4,5$ and 6 were supported.

Conscientiousness, however, was not found to have a significant relationship with WRE use after hours $(r=.11)$; therefore hypothesis 2 was not supported. Table 2 reports the means, standard deviations, and correlations between WRE use after hours and the individual, job, and workplace factors examined in this study.

Hypothesis 7 proposed positive relationships between WRE use after hours and the three dimensions of burnout. Emotional exhaustion was not found to have a significant relationship with WRE use after hours $(r=-.04)$. However, cynicism $(r=$ -.20) and reduced personal accomplishment $(r=-.32)$ were found to have significant negative relationships with WRE use after hours, which was in the opposite direction of what was hypothesized. Therefore, hypotheses 7a, 7b, and 7c were not supported. 
Table 2. Means, standard deviations, and intercorrelations among all study variables.

\begin{tabular}{|c|c|c|c|c|c|c|c|c|c|c|c|c|c|}
\hline & & Mean & SD & 1 & 2 & 3 & 4 & 5 & 6 & 7 & 8 & 9 & 10 \\
\hline 1 & WRE Use & 3.36 & 1.46 & & & & & & & & & & \\
\hline 2 & Telepressure & 3.30 & .89 & $.27^{*}$ & & & & & & & & & \\
\hline 3 & Conscientiousness & 3.92 & .73 & .11 & .04 & & & & & & & & \\
\hline 4 & Job Relevance & 2.99 & 1.27 & $.75^{*}$ & .13 & .08 & & & & & & & \\
\hline 5 & Perceived Usefulness & 3.20 & 1.30 & $.78^{*}$ & $.18^{*}$ & .04 & $.80 *$ & & & & & & \\
\hline 6 & Others' WRE Use & 3.82 & .86 & $.32 *$ & -.17 & .11 & $.31 *$ & $.30 *$ & & & & & \\
\hline 7 & Expectations of Use & 2.43 & 1.15 & $.46^{*}$ & .11 & -.01 & $.62 *$ & $.55^{*}$ & $.31 *$ & & & & \\
\hline 8 & Emotional Exhaustion & 3.94 & 1.75 & -.04 & $.32 *$ & $-.24 *$ & -.04 & -.05 & -.13 & .10 & & & \\
\hline 9 & Cynicism & 3.35 & 1.67 & $-.20 *$ & $.18^{*}$ & $-.23 *$ & $-.19 *$ & $-.24 *$ & $-.18^{*}$ & -.01 & $.72 *$ & & \\
\hline 10 & $\begin{array}{l}\text { Reduced Personal } \\
\text { Accomplishment }\end{array}$ & 2.08 & .85 & $-.32 *$ & -.10 & $-.18^{*}$ & $-.28 *$ & $-.29 *$ & $-.20 *$ & $-.20 *$ & $.21^{*}$ & $.36^{*}$ & \\
\hline 11 & Voluntariness & 4.13 & .83 & $-.35^{*}$ & $-.21 *$ & -.05 & $-.45^{*}$ & $-.29 *$ & -.12 & $-.44 *$ & -.04 & -.05 & .08 \\
\hline
\end{tabular}

Note. ${ }^{*} p<.05$; sample size ranges from $124-131$ 
Several questions were included in the survey to better understand how keeping up with WRE after hours relates to different demographic characteristics. Participants were asked to report their age, gender, job tenure, and organizational tenure. In addition, they were asked to provide information on their job status and responsibilities, such as their job title, salary, number of individuals supervised, number of supervisors, and whether their workplace allows them to work from home. Variables related to family responsibilities, such as marital status, number of children, whether employees are in a caregiver role, the percent of household tasks they are responsible for, and whether they receive help from others for household tasks were also assessed. Lastly, employees were asked whether they had their WRE account connected to their smartphone, and whether they used their WRE for personal communications. See the Appendix for a full list of the demographic questions.

The use of WRE after hours was found to have a significant relationship with gender $(r=-.19)$, such that males reported keeping up with their WRE more than females. Salary range also had a significant relationship with WRE use after hours $(r=$ .34), with those employees reporting higher salaries also reporting greater use of their WRE after hours. Employees with jobs that allowed them to work from home were significantly more likely to keep up with their WRE after hours $(r=.23)$. In terms of accessibility to WRE, those that had access to their WRE on their smartphone reported keeping up with their WRE after hours to a significantly larger degree $(r=.67)$. Lastly, employees using their WRE email account for personal purposes were less likely to keep up with their WRE after hours $(r=-.18)$. See table 3 for intercorrelations among WRE use after hours and all demographic variables examined in this study. 
Table 3. Intercorrelations among WRE email use after hours and all demographic variables.

\begin{tabular}{|c|c|c|c|c|c|c|c|c|c|c|c|c|c|c|c|c|c|}
\hline & & 1 & 2 & 3 & 4 & 5 & 6 & 7 & 8 & 9 & 10 & 11 & 12 & 13 & 14 & 15 & 16 \\
\hline 1 & WRE Use & & & & & & & & & & & & & & & & \\
\hline 2 & Age & .04 & & & & & & & & & & & & & & & \\
\hline 3 & Gender & $-.19^{*}$ & $.21^{*}$ & & & & & & & & & & & & & & \\
\hline 4 & Job Tenure & -.04 & $.61^{*}$ & .15 & & & & & & & & & & & & & \\
\hline 5 & $\begin{array}{l}\text { Organizational } \\
\text { Tenure }\end{array}$ & -.11 & $.46^{*}$ & .13 & $.59 *$ & & & & & & & & & & & & \\
\hline 6 & Job Title & -.02 & .07 & .15 & $.24 *$ & $.19^{*}$ & & & & & & & & & & & \\
\hline 7 & Salary & $.34 *$ & .16 & .04 & .05 & $.29^{*}$ & -.01 & & & & & & & & & & \\
\hline 8 & $\begin{array}{l}\text { Individuals } \\
\text { Supervised }\end{array}$ & .12 & .09 & -.12 & .03 & .07 & -.07 & .07 & & & & & & & & & \\
\hline 9 & $\begin{array}{l}\text { Number of } \\
\text { Supervisors }\end{array}$ & .03 & -.07 & .06 & -.08 & -.08 & .05 & .00 & .14 & & & & & & & & \\
\hline 10 & $\begin{array}{l}\text { Work from } \\
\text { Home }\end{array}$ & $.23 *$ & -.06 & -.02 & -.10 & -.09 & -.10 & $.22^{*}$ & .14 & .01 & & & & & & & \\
\hline 11 & Marital Status & .01 & -.16 & -.08 & -.05 & -.04 & .13 & -.05 & .09 & .18 & .10 & & & & & & \\
\hline 12 & $\begin{array}{l}\text { Number of } \\
\text { Children }\end{array}$ & -.04 & $.53^{*}$ & .17 & $.22 *$ & $.34 *$ & .09 & $.19^{*}$ & -.13 & -.04 & -.01 & -.10 & & & & & \\
\hline 13 & Caregiver Role & .10 & $.23^{*}$ & .11 & .03 & .05 & .09 & .01 & -.10 & -.11 & .07 & -.13 & $.42 *$ & & & & \\
\hline 14 & Responsibility & .14 & .15 & -.05 & .14 & .11 & .08 & $.19^{*}$ & .16 & .07 & .07 & .13 & .16 & .05 & & & \\
\hline 15 & $\begin{array}{l}\text { Household } \\
\text { Help }\end{array}$ & -.14 & -.02 & $.22 *$ & -.12 & -.08 & -.12 & -.09 & -.14 & -.02 & -.10 & $-.23 *$ & .08 & .12 & $-.70^{*}$ & & \\
\hline 16 & $\begin{array}{l}\text { WRE on } \\
\text { Smartphone }\end{array}$ & $.67 *$ & .07 & $-.20^{*}$ & .09 & -.02 & -.05 & $.29 *$ & .06 & -.05 & .08 & -.04 & -.01 & -.01 & .14 & -.13 & \\
\hline 17 & $\begin{array}{l}\text { Personal Use } \\
\text { of WRE }\end{array}$ & $-.18^{*}$ & .07 & .10 & .10 & .06 & .02 & .00 & $-.20 *$ & -.13 & $-.20^{*}$ & -.09 & .10 & .02 & -.07 & -.02 & $-.19 *$ \\
\hline
\end{tabular}

Note. $* p<.05$; sample size ranges from 121-131 


\section{Regression Analysis}

To further examine the influence of individual, job, and workplace factors on employees' use of WRE after hours, a hierarchical multiple regression was conducted to test the unique contribution of each predictor. Gender, salary range, the ability to work from home, employees' access to WRE on their smartphone, and the use of WRE for personal purposes were entered in Step One as control variables $\left[R^{2}=.50, F(5,116)=\right.$ $23.01, p<.01]$. Only the ability to work home $(\beta=.17, p=.02)$ and WRE access on a smartphone $(\beta=.62, p<.01)$ were found to significantly predict WRE use after hours. Telepressure, conscientiousness, job relevance, perceived usefulness, perceptions of others' WRE use after hours, and subjective expectations of WRE use after hours were entered in Step Two, which resulted in a significant increase in $R^{2}(\Delta R=.25, p<.01)$. The overall regression model was significant, and was found to predict $74 \%$ of the variance in WRE use after hours $\left[R^{2}=.74, F(11,110)=28.90, p<.01\right]$. Specifically, telepressure $(\beta=.15, p=.01)$, job relevance $(\beta=.21, p=.03)$, and perceived usefulness $(\beta=.38, p<.01)$ were found to predict unique variance in WRE use after hours. See table 4 for the full results of the regression analysis. 
Table 4. Individual, job, and workplace factors predicting WRE use after hours.

\begin{tabular}{|c|c|c|c|c|c|c|}
\hline & $B$ & $S E(B)$ & $\beta$ & $R$ & $R^{2}$ & $\Delta R^{2}$ \\
\hline Step 1 & & & & .71 & $.50^{*}$ & \\
\hline Constant & 2.33 & .79 & & & & \\
\hline Gender & -.36 & .38 & -.07 & & & \\
\hline Salary & .10 & .08 & .09 & & & \\
\hline Work from Home & .62 & .26 & $.17^{*}$ & & & \\
\hline WRE on Smartphone & 1.90 & .22 & $.62 *$ & & & \\
\hline Personal use of WRE & -.07 & .23 & -.02 & & & \\
\hline Step 2 & & & & .86 & $.74^{*}$ & $.25 *$ \\
\hline Constant & -.93 & .78 & & & & \\
\hline Gender & -.15 & .29 & -.03 & & & \\
\hline Salary & -.03 & .06 & -.03 & & & \\
\hline Work from Home & .28 & .19 & .08 & & & \\
\hline WRE on Smartphone & .95 & .19 & $.31^{*}$ & & & \\
\hline Personal use of WRE & .18 & .17 & .05 & & & \\
\hline Telepressure & .25 & .09 & $.15^{*}$ & & & \\
\hline Conscientiousness & .11 & .10 & .06 & & & \\
\hline Job Relevance & .25 & .11 & $.21^{*}$ & & & \\
\hline Perceived Usefulness & .44 & .10 & $.38^{*}$ & & & \\
\hline Others' WRE use & .16 & .09 & .10 & & & \\
\hline Expectations of use & -.02 & .08 & -.02 & & & \\
\hline
\end{tabular}

\section{Moderation Analyses}

The PROCESS macro, version 2.12.1, developed for SPSS (Hayes, 2013) was used to conduct moderation analyses. Three models, corresponding with hypotheses $8 \mathrm{a}$, $8 \mathrm{~b}$, and $8 \mathrm{c}$, were tested. All variables were mean centered at zero. Model 1 examined the moderating effect of voluntariness on the relationship between WRE use after hours and the emotional exhaustion component of burnout. The model yielded a significant 
interaction effect, $b=-.31,95 \% \mathrm{CI}[-.61,-.01], t=-2.06, p=.04$, indicating that the relationship between WRE use after hours and emotional exhaustion is moderated by voluntariness (see Figure 5). The $R^{2}$ increase associated with the interaction term was .03, $F(1,120)=4.24, p=.04$. Thus, hypothesis 8 a was supported.

To further interpret the moderation effects in Model 1, simple slopes were examined at low, moderate, and high levels of voluntariness. Results showed that when voluntariness is low (-1 SD), there is a positive effect of WRE use after hours on emotional exhaustion $(b=.27,95 \%$ CI $[-.13, .67], t=1.33, p=.19)$, and when voluntariness is high $(+1 \mathrm{SD})$, there is a negative effect of WRE use after hours on emotional exhaustion $(b=-.26,95 \%$ CI $[-.54, .03], t=-1.78, p=.08)$. The effect of WRE use after hours on emotional exhaustion at moderate levels of voluntariness (mean) were near-zero $(b=.01,95 \%$ CI $[-.23, .24], t=.04, p=.97)$. The effects at all three levels of the moderator were not statistically significant; however, it should be noted that given the small sample size in each simple slope analysis (ranging from 23 to 66), the lack of statistical significance in these analyses is not surprising, although the effects are all in the expected directions.

Model 2 examined the moderation effect of voluntariness on the relationship between WRE use after hours and cynicism. The model did not yield a significant interaction effect, $b=-.25,95 \% \mathrm{CI}[-.53, .04], t=-1.72, p=.09$, suggesting that voluntariness does not moderate the relationship between WRE use after hours and cynicism. Hypothesis $8 \mathrm{~b}$ was not supported.

Model 3 examined the moderating effect of voluntariness on the relationship between WRE use after hours and reduced personal accomplishment. The model yielded 
a significant interaction effect, $b=-.17,95 \%$ CI $[-.31,-.03], t=-2.37, p=.02$, indicating that the relationship between WRE use after hours and reduced personal accomplishment is moderated by voluntariness (see Figure 6). The $R^{2}$ increase due to the interaction term was $.04, F(1,120)=5.63, p=.02$. Thus, hypothesis $8 \mathrm{c}$ was supported.

Simple slopes were examined at three levels of voluntariness in Model 3. Results showed that there is a significant negative relationship between WRE use after hours and reduced professional accomplishment when voluntariness is high $(b=-.29,95 \%$ CI [-.42, $-.16], t=-4.36, p<.01)$ and moderate $(b=-.15,95 \%$ CI $[-.26,-.04], t=-2.71, p=.01)$. At low levels of voluntariness, the correlation between WRE use after hours and reduced professional accomplishment was not significantly different from zero $(b=-.01,95 \% \mathrm{CI}$ $[-.20, .17], t=-.12, p=.91)$.

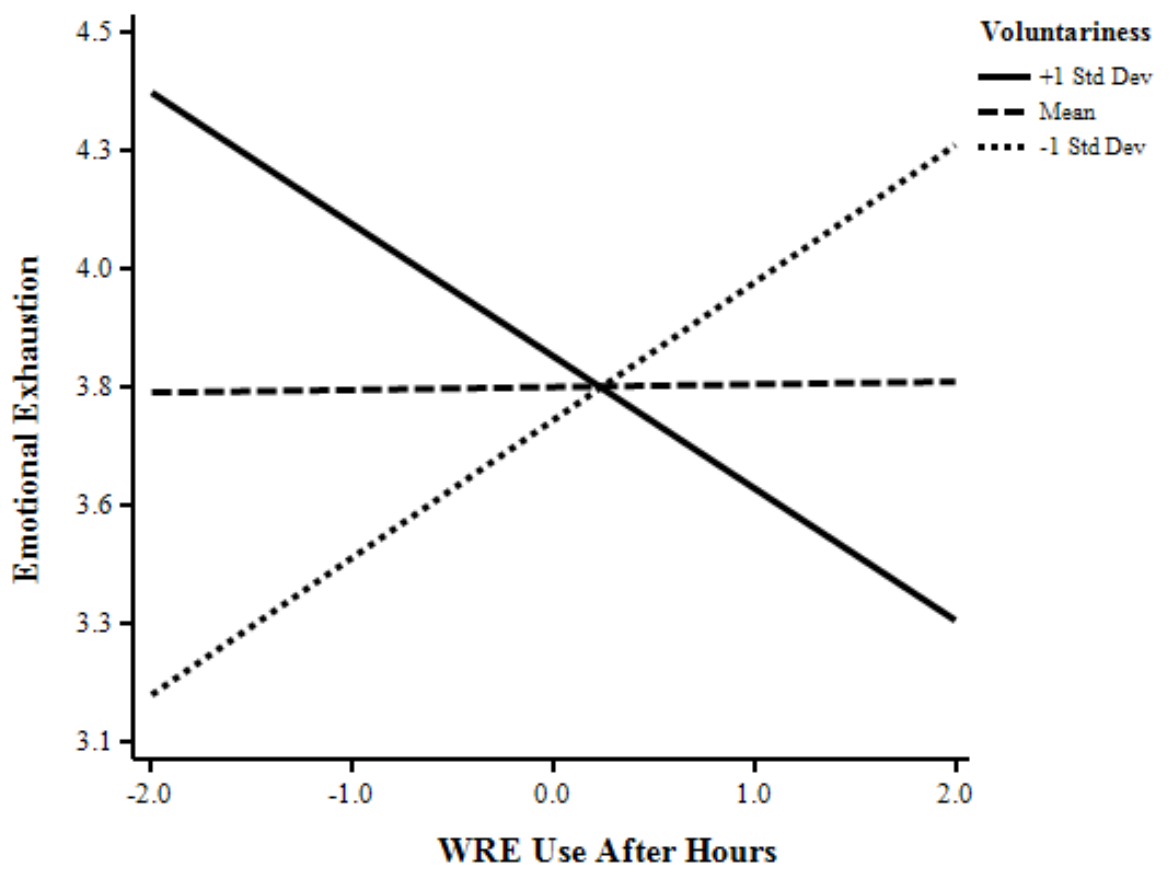

Figure 5. The moderating effect of voluntariness on the relationship between emotional exhaustion and WRE use after hours. 


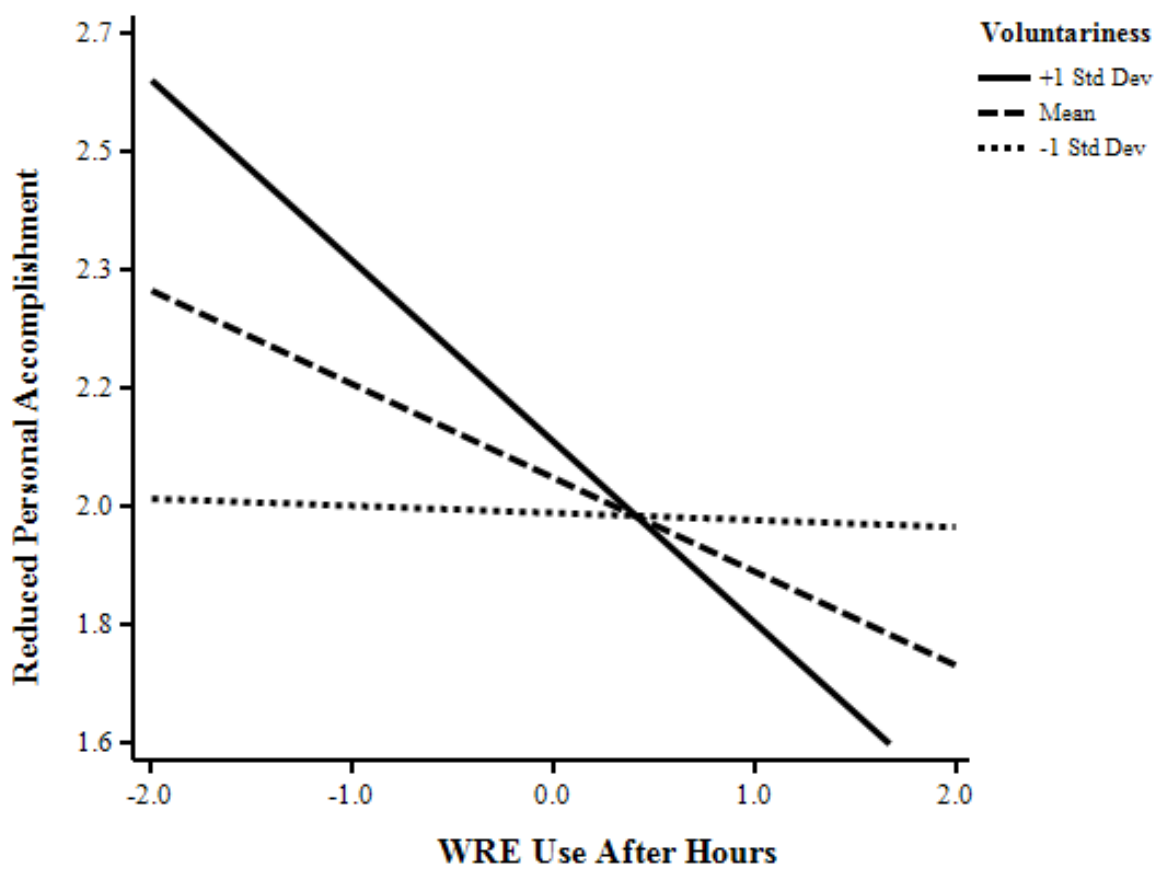

Figure 6. The moderating effect of voluntariness on the relationship between reduced personal accomplishment and WRE use after hours

\section{Supplemental Analyses}

Model testing. To further examine the process through which workplace, job, and individual factors influence WRE after hours, and the effect of WRE use after hours on burnout, structural equation modeling (SEM) was used to test the overall path model presented in this study. The proposed path model (Figure 2) was tested using SPSS AMOS v.21 to obtain parameter estimates for direct and indirect effects. SEM allows for the assessment of model fit through providing several goodness-of-fit indices, which indicate how well the theoretical model fits the data. Goodness of fit was examined though evaluating a variety of absolute, relative, and penalty fit indices. The model will be concluded to have good fit if the overall chi-square divided by degrees of freedom $\left(\chi^{2} / \mathrm{df}\right)$ is below 3 , the root mean square error of approximation (RMSEA) is less than .08, 
the p-value for the test of close fit (PCLOSE) is non-significant (i.e., above .05), and the comparative fit index (CFI) and the Tucker-Lewis index (TLI) are greater than .95 (Bollen \& Long, 1993). Based on these criteria, the proposed model was found to have poor fit $\left(\chi^{2} / \mathrm{df}=17.03 ; \mathrm{RMSEA}=.35 ;\right.$ PCLOSE $\left.<.01 ; \mathrm{CFI}=.16 ; \mathrm{TLI}=-.29\right)$.

Comparing means across demographic categories. To further examine the relationships between WRE use after hours and correlated variables, a series of independent samples t-tests and a one-way analysis of variance were conducted. First, a ttest was conducted to examine the difference in means across gender. Levene's test for equality of variance was significant $(F=18.32, p<.05)$, and therefore, equal variances were not assumed. Results showed that males $(M=4.36, S D=.49, n=9)$ were significantly more likely to keep up with their WRE after hours than females $(M=3.30$, $S D=1.48, n=113), t(23)=4.98, p<.01$.

Next, a one-way analysis of variance, with salary range as the independent variable and WRE use after hours as the dependent variable was conducted. Results showed a main effect for salary range, $F(5,124)=5.61, p<.01$. Generally, means were found to increase as salary increased. The mean of WRE after hours for the $\$ 20 \mathrm{~K}$ to $<$ $\$ 30 \mathrm{~K}$ salary range $(n=21)$ was $2.95(S D=1.55)$, a mean of $2.68(S D=1.47)$ was found for the $\$ 30 \mathrm{~K}$ to $<\$ 40 \mathrm{~K}$ salary range $(n=43)$, a mean of $3.72(S D=1.26)$ was found for the $\$ 40 \mathrm{~K}$ to $<\$ 50 \mathrm{~K}$ salary range $(n=40)$, a mean of $4.20(S D=1.14)$ was found for the $\$ 50 \mathrm{~K}$ to $<\$ 60 \mathrm{~K}$ salary range $(n=14)$, a mean of $4.31(S D=1.01)$ was found for the $\$ 60 \mathrm{~K}$ to $<\$ 70 \mathrm{~K}$ salary range $(n=9)$, and a mean of $4.67(S D=.29)$ was found for the $\$ 70 \mathrm{~K}$ to $<\$ 80 \mathrm{~K}$ salary range $(n=3)$. Results of Tukey's post hoc test suggest that the $\$ 30 \mathrm{~K}$ to $<\$ 40 \mathrm{~K}$ salary range significantly differs from the $\$ 40 \mathrm{~K}$ to $<\$ 50 \mathrm{~K}, \$ 50 \mathrm{~K}$ to $<$ 
$\$ 60 \mathrm{~K}$, and $\$ 60 \mathrm{~K}$ to $<\$ 70 \mathrm{~K}$ salary ranges. Since no one reported falling into the $<\$ 20 \mathrm{~K}$ and $\$ 90 \mathrm{~K}$ to $<\$ 100 \mathrm{~K}$ salary ranges, and only one employee reported falling into the $\$ 100 \mathrm{~K}$ or more salary range, these categories were not included in the analysis.

The means of those reporting that their office allowed them to work from home and those reporting that they were not allowed to work from home were compared using a t-test. Levene's test for equality of variance was significant $(F=8.77, p<.01)$, and therefore, equal variances were not assumed. Results showed that those who were allowed to work from home $(M=4.10, S D=1.14, n=23)$ were significantly more likely to keep up with their WRE after hours than those who were not allowed to work from home $(M=3.21, S D=1.48, n=99), t(41)=-3.17, p<.01$.

A t-test was also conducted to compare means of groups with access to their WRE on their smartphone and groups with no access. Levene's test for equality of variance was not significant $(F=.98, p=.32)$, and therefore, equal variances were assumed. Results showed those with access to their WRE on their smartphone $(M=4.07, S D=1.05, n=$ 81) were significantly more likely to keep up with their WRE after hours than those reporting that they did not have access to their WRE on their smartphone $(M=2.00, S D=$ $1.15, n=41), t(120)=-9.95, p<.01$.

Finally, a t-test comparing the means of those who use their WRE for personal purposes and those that did not was conducted. Levene's test for equality of variance was not significant $(F=1.73, p=.19)$, and therefore, equal variances were assumed. Results showed that those reporting the use of their WRE for personal communications were less likely to keep up with their WRE after hours $(M=2.95, S D=1.56, n=33)$ than those 
that did not use their WRE account for personal purposes $(M=3.53, S D=1.40, n=89)$, $t(120)=2.00, p=.05$. 


\section{DISCUSSION}

This study aimed to better understand the antecedents and consequences of WRE use after work hours. More specifically, variables related to the individual, job, and workplace were examined as predictors of WRE use after hours, and burnout was examined as an outcome. In addition, the moderating effect of voluntariness on the relationships between WRE use after hours and the three burnout dimensions was also tested.

\section{Antecedents of Work-Related Email Use After Hours}

WRE use after hours was found to have a positive relationship with several individual (i.e., telepressure), job (i.e., job relevance and perceived usefulness), and workplace factors (i.e., perceptions of others' WRE use after hours and subjective expectations of use). Conscientiousness, however, was not found to have a significant relationship with WRE use after hours. Conscientious individuals are characterized as goal-oriented, reliable, responsible, and practical (Goldberg, 1992). Although these characteristics may influence workplace behaviors, they may also apply to behaviors after work hours. For example, conscientious individuals may not only be reliable to their supervisors and coworkers, but may also be dependable to others outside of work, such as friends, partners, or children. In addition, conscientious individuals may be more practical, in the sense that they see the importance of detaching from work after hours and devoting "free" time to recover resources lost during the work day. Being goaloriented, conscientious individuals may also set and strive to meet goals both inside and 
outside the workplace, such as goals relating to physical health, mental health, family, or personal development.

It is important to note that conscientiousness was the only antecedent included in the study model which was not specific to the use of WRE after hours. For example, telepressure, along with the job and workplace factors examined, specifically related to the pressure to respond to WRE after hours, perceptions of the importance and relevance of using WRE after hours, and the degree to which it is the norm in the workplace to use WRE after hours, respectively. Therefore, conscientiousness individuals may be more likely to be conscientious in all aspects of life rather than only in relation to WRE use. Indeed, the measure of conscientiousness used in the present study asked participants to indicate to what extent statements such as "Get chores done right away" and "Like order" described them. These statements can refer to both home and work life, and therefore, individuals completing the measure may be considering their conscientious behavior across multiple domains rather than specifically in relation to work.

In addition to examining individual relationships, the unique contribution of each antecedent in predicting WRE use after hours was also examined. Findings suggest that telepressure, job relevance, and perceived usefulness are unique predictors of WRE use after hours. Workplace related factors became nonsignificant when examined in conjunction with individual (i.e., telepressure) and job factors. These findings suggest that individuals' perceptions or opinions about the relevance of WRE use after hours to job, the degree to which they think it is useful for their job performance, and the degree to which individuals feel compelled to respond to WRE after hours have the strongest influence on one's decision to use WRE after hours, compared to their perceptions of 
descriptive and injunctive norms in the workplace. Even if individuals feel that there is a norm in the workplace to use WRE after hours (i.e., through the observed behavior of their supervisors/coworkers or their perceptions of supervisors' expectations of keeping up with WRE after work), employees' perceptions of job factors and the amount of telepressure they feel play a larger role in determining whether they keep up with their WRE after hours.

\section{Work-Related Email Use After Hours and Burnout}

The three dimensions of burnout (i.e., emotional exhaustion, cynicism, and a reduced sense of personal accomplishment) were examined as consequences of WRE use after hours. Although it was predicted that all three dimensions would have a positive relationship with WRE use after hours, findings suggest that emotional exhaustion does not have a significant relationship with WRE use after hours, and cynicism and reduced professional accomplishment have a negative relationship with WRE use after hours.

According to the job demands-resources model, emotional exhaustion can be considered a consequence of high job demands paired with a lack of resources to meet those demands (Bakker et al., 2004; Bakker et al., 2005; Lee \& Ashforth, 1996). Keeping up with WRE after hours was initially hypothesized as an additional job demand, given that it may result in a self-assigned increase in workload. However, keeping up with WRE after hours may actually be functioning as a job resource, by allowing employees to better manage their work demands. Those that keep up with their WRE after work hours may actually be keeping up with the demands of their job, and therefore may not feel that they have to get "caught up" during work hours. Demerouti et al. (2001) define job 
demands as aspects of the job that require sustained physical or psychological effort from employees, and being that WRE is just one component of office and administrative jobs, spreading out the mental tax of keeping up with WRE over both work and nonwork hours may allow employees to better meet other job demands during work hours, such as clerical work, administrative duties, or office management tasks.

Since emotional exhaustion is often considered to be the core component of burnout (see Demerouti et al., 2001; Halbesleben \& Bowler, 2007; Shirom, 2003), an alternative path model in which cynicism and reduced personal accomplishment were removed as outcome variables was tested. In this model, the two workplace factors and conscientiousness were removed as predictors, and perceived usefulness and job relevance were considered indicators of one latent factor, since these two variables were found to be highly correlated. This alternative model was found to have poor fit $\left(\chi^{2} / \mathrm{df}=\right.$ 36.43; RMSEA $=.52 ;$ PCLOSE $<.01 ; \mathrm{CFI}=.35 ; \mathrm{TLI}=-.30)$.

Cynical employees are often characterized as unmotivated and disengaged from their work (Maslach et al., 2001). Findings from the present study suggest that individuals using WRE after hours are less cynical, implying that they are more motivated and engaged in their work. Arguably, WRE use after hours may be driven by employees' motivation and engagement in their work. Indeed, organizational citizenship behavior, which WRE use after hours can be characterized as, has been found to have a positive relationship with engagement and motivation (Gupta, Agarwal, \& Khatri, 2016; Pohl, Dal Santo, \& Battistelli; 2012). Conversely, cynical employees may be more likely to put in minimal effort in their job, and therefore, these individuals may choose not to work after work hours. This conclusion may be supported by research findings that 
cynicism has a negative relationship with organizational citizenship behavior (Jordan, Schraeder, Field, \& Armenakis, 2007; Payne, 2013; Schepman \& Zarate, 2008). The direction of the relationship between WRE use after hours and cynicism, however, should be further examined using longitudinal methodology.

WRE use during nonwork hours was also found to have a negative relationship with reduced personal accomplishment, suggesting that those who keep up with their WRE after work hours may feel a greater sense of self-efficacy and competence. An explanation for this finding could be that employees may be reaping the benefits of working after hours through positive feedback, positive performance appraisals, or promotions. Indeed, in a meta-analysis by Podsakoff et al. (2009), organizational citizenship behavior was found to have positive relationships with supervisor-ratings of job performance and employee rewards. The direction of the relationship between WRE use and reduced personal accomplishment should also be further examined in future research. Arguably, those that have a higher sense of personal accomplishment, developed through receiving high performance ratings and greater rewards, may be the ones more likely to keep up with their WRE use after hours in order to meet the expectations of their supervisors and/or the organization.

Given that burnout dimensions, most notably cynicism and reduced personal accomplishment, could be conceptualized as predictors of WRE use after hours, an alternative model in which the three burnout dimensions, along with the six individual, job, and workplace factors, predict WRE use after hours was tested. This model was found to have poor fit $\left(\chi^{2} / \mathrm{df}=10.84 ; \mathrm{RMSEA}=.28 ;\right.$ PCLOSE $<.01 ; \mathrm{CFI}=.27 ; \mathrm{TLI}=-$ $.12)$. 
The influence of one's segmentation or integration preference on the relationship between WRE use after hours and burnout should be examined in future research. Individuals can differ in their preference to segment or integrate their work and home domains. "Segmenters" are individuals who strive to create strict boundaries between work and home domains through not allowing events or issues in one domain to spill over into another. "Integrators," on the other hand, prefer to remove or minimize boundaries between work and home, and may even blend facets of the two domains. For example, while segmenters might avoid talking about work, thinking about the job, or conducting work while at home, integrators may talk about their work day while with their family or keep up with work issues while at home (Kreiner, 2006).

For individuals with an integration preference, work-related technology may actually facilitate a desired integration between work and home domains, and may aid in developing a healthy balance between the two domains (Valcour \& Hunter, 2005). In a qualitative study examining boundary management in Episcopal parish priests, Kreiner, Hollensbe, and Sheep (2009) found that a healthy facilitation of work-home domain integration can occur with active management of work-related technology. For example, checking WRE after hours may allow employees to screen for important or urgent emails, and keep non-emergencies out of their home domain. Checking WRE after hours may also give employees the time to craft responses or think through issues rather than immediately responding to work-related matters, which may act as a strategy to better manage work demands. Therefore, it is likely that those who prefer to integrate their work and home domains are more likely to use WRE as a strategy to facilitate a healthy integration between the two. 


\section{The Moderating Effect of Voluntariness}

Voluntariness was examined as a moderator of the relationships between WRE use after hours and burnout dimensions. It was predicted that the degree to which individuals feel the use of WRE after hours is mandatory will influence whether they experience burnout as a result of keeping up with their WRE after hours. Voluntariness was found to moderate the relationship between WRE use after hours and emotional exhaustion, such that for those who keep up with their WRE after hours, having a higher sense of voluntariness (i.e., feeling that keeping up with WRE after hours is not mandatory) is associated with lower emotional exhaustion. Conversely, those who feel that keeping up with WRE after hours is mandatory (i.e., lower voluntariness) experience greater emotional exhaustion as a result of their WRE use after hours. These findings suggest that for employees who make the personal choice to keep up with their WRE after hours, voluntariness may be acting as a job resource, helping them to keep up with their job demands while "off the clock." However, those individuals with low voluntariness may view keeping up with WRE after hours as an additional job demand, which could increase the likelihood of experiencing emotional exhaustion.

Voluntariness was also found to moderate the relationship between WRE use and reduced personal accomplishment. The more people feel WRE use after hours is voluntary, the more negative the relationship between WRE use and reduced personal accomplishment becomes. In other words, if an employee feels keeping up with WRE after hours is not mandatory, and they choose to keep up with their WRE after hours on their own accord, the more likely they are to feel a sense of personal accomplishment. On the other hand, when voluntariness is low, WRE use after hours has no relationship with 
reduced personal accomplishment, suggesting that engaging in this behavior has no impact on one's sense of self-efficacy and competence when they feel they have no say in keeping up with their WRE after hours. These findings suggest that factors such as autonomy can aid in one's perceptions of personal growth and accomplishment, and the relationship between autonomy and WRE use after hours should be explored in future research.

\section{Work-Related Email Use After Hours and Demographic Characteristics}

The relationships between WRE use after hours and several demographic characteristics were examined. WRE use after hours was found to have a negative relationship with gender, such that males were more likely to keep up with their WRE after hours than female. However, it should be noted that there were only nine men in the sample, and therefore these results are likely not robust. Future research should aim to capture more male employees in the sample in order to examine differences across gender.

WRE use after hours was found to have a positive relationship with salary range. Employees are likely to be given more responsibilities as their salary increases, and therefore, may be sending and checking their WRE after hours to keep up with their work demands. WRE was also found to have a positive relationship with the ability to work from home, such that those reporting that their workplace allows them to work from home also report that they keep up with WRE after work hours to a greater extent. This finding may suggest that it is more likely for the line between work and home domains to be blurred when the physical space for these two domains is the same. This conclusion is 
supported by research by Sonnentag et al. (2010), who found that having an office in one's home had a negative relationship with psychological detachment, suggesting that those who maintain a thin line between their work and home domains are less likely to mentally distance themselves from the workplace. In addition, employees that have the capability to work from home may feel that they are expected to keep up with their WRE while at home, even if it is after hours.

Having WRE access on one's smartphone was found to have a strong positive relationship with WRE use after hours, suggesting that when WRE is more accessible, the likelihood of reading, checking, or sending WRE after hours increases. When employees have access to their WRE on portable devices, they are able to check their WRE at any time. Future research may wish to examine whether this behavior may occur more frequently if they receive pop-up notifications on their smartphones when WRE are received. Arguably, being made aware through notifications that a WRE has been received could increase the temptation to read or respond to WRE, especially for those individuals that are high in telepressure.

Unexpectedly, the use of WRE for personal reasons was found to have a negative relationship with WRE use after hours, suggesting that those who use their WRE accounts for personal purposes (e.g., emailing friends and family, signing up for promotions, making online purchases, etc.), are less likely to read, respond to, and send WRE after hours. Although future research is necessary to form more concrete conclusions based on these findings, one explanation may be that individuals who do not check their personal emails frequently are also less likely to check their WRE after hours. In addition, if employees' WRE accounts are being used for personal communications, 
they may be addressing these personal communications during the work day as well. This may decrease the necessity to check their WRE account after hours for personal reasons.

\section{Limitations}

Although this study yielded novel findings that contribute to the emerging research on WRE use after hours, there are some limitations that should be noted and addressed by future research. First, cross-sectional data was collected in this study, which does not allow for causal inferences. However, given that this is the first study to examine a model of antecedents and consequences of WRE use after hours, crosssectional data may be appropriate for initial stages research in this area. Future studies should take a longitudinal approach to capture a more holistic picture of how the proposed relationships evolve over time. For example, as previously mentioned, the direction of the relationships that WRE use after hours has with cynicism and reduced personal accomplishment should be further examined, given that those who are less cynical about their work and have a higher sense of personal accomplishment may be more likely to keep up with their WRE use after hours.

Second, data was gathered using self-report surveys, which makes common method bias a possible limitation (Podsakoff, MacKenzie, Lee, \& Podsakoff, 2003). Although the results of Harman's one-factor test show little evidence for a common factor augmenting the relationships found, results should still be interpreted with caution, as there still may be potential concerns relating to common method bias. To address this limitation, future research should use more objective measures or other-report data for assessing WRE use after hours and organizational norms (i.e., workplace factors). For 
example, the numbers of emails sent, received, and checked by employees after work hours could be tracked and tallied, which is a more objective method of measuring the degree to which employees keep up with their WRE after hours. The amount of time employees spend keeping up with their WRE after hours could also serve as an indicator of the degree to which they engage in this behavior. In addition, factors such as the length, topic, content, and intensity of an email can impact whether employees read, check, or respond to emails. Therefore, future research should aim to explore how factors such as email length and content impact employees' WRE use after hours, and whether checking and responding to particular types of email (e.g., lengthy emails that require detailed responses) is influenced by different individual, job, and workplace factors. The types of emails being sent and received may also have differential effects on employee well-being outcomes, such as components of employee burnout.

The workplace factors examined in this study could be measured through collecting data from supervisors and coworkers. To support the degree to which employees perceive others in this workplace to keep up with their WRE after hours, selfreported use or tracked WRE usage after hours could be collected from supervisors and coworkers as well. In addition, supervisors could be asked to rate the degree to which they expect their employees to keep up with their WRE after hours, which could support one's subjective expectations to engage in this behavior. Using other-report or more objective versions of these measures can not only help in avoiding common method bias, but when administered in conjunction with self-report measures of these variables, can also help to identify any differences between employees' perceptions of workplace norms and more objective workplace norms related to use of WRE after hours. 
Third, in the present study, the four-item measure of conscientiousness was found to have a low Cronbach's alpha $(\alpha=.55)$, indicating that this measure has low internal consistency and that the items in this measure do not strongly relate to one another. The alphas resulting from the deletion of items in the measure were also calculated, and through removing the one reversed scored item in the measure, Cronbach's alpha increased to .60 . However, since this was not a large increase, the increase did not bring the alpha of the measure to an acceptable level, and the results of analyses involving conscientiousness did not significantly change due to using a three-item version of the scale, the full four-item measure was kept for all analyses. Gosling, Rentfrow, and Swann (2003) suggest that there is a psychometric cost of using shortened forms of measures (e.g., the Mini-IPIP conscientiousness measure used in the present study). When attempting to measure a broad construct with a short scale, the shortened measure may have lower internal consistency. Therefore, Gosling et al. suggest that test-retest may be a more appropriate measure of reliability for shortened measures. In addition, although the Mini-IPIP conscientiousness measure is a well-established measure which has been shown to have an acceptable internal consistency in previous research (Donnellan et al., 2006), future research may wish to use alternative measures of conscientiousness, such as those from International Personality Item Pool (Goldberg, 1999) or the NEO-PI-R (Costa $\&$ McCrae, 1992). Alternative measures may allow for the assessment of conscientiousness at the facet level as well, which can aid in identifying differential relationships between conscientiousness facets and the use of WRE after hours. In the present study, two of four items in the conscientiousness measure capture the "orderliness" facet of the construct. Therefore, using a broader multi-faceted measure 
will allow for the examination of relationships across different conscientiousness facets, such as self-efficacy, achievement-striving, and dutifulness.

Next, SEM was used to test the full model of antecedents and consequences of WRE use after hours proposed in this study, which was found to have poor fit. There may be several reasons why poor model fit was found. First, a sample size of 131 was obtained in the present study. Although this sample size is adequate to conduct correlational and regression analyses, for goodness-of-fit tests, to achieve a power of . 80 to detect a small to medium effect of .30 (Cohen, 1988) at an alpha level of .05, a minimum sample size of 210 is necessary. Future research should aim to meet this minimum sample size requirement when testing the full model of antecedents and consequences proposed. In addition, the number of variables in a model can affect model fit. For example, TLI and CLI can worsen as variables are added to the model (Kenny \& McCoach, 2003). Given that the present model included a total of eleven variables, testing smaller models of just antecedents or consequences of WRE use after hours may result achieving adequate fit.

Lastly, the present study focused only on a sample of salaried administrative assistants and office workers, which limits the generalizability of these findings to other occupations and employee types. For example, findings may differ across exempt and non-exempt employees, given that sending or responding to WRE after hours may be considered overtime work. In addition, different occupations rely on email to different degrees, and therefore, findings may differ across professions. For example, although email is highly relevant to the work of office workers, those working in the retail industry may not be as heavily reliant on email for day-to-day work. Future research should test 
the relationships proposed in the present dissertation in a more inclusive sample with employees across various occupations. One method to collect data across various occupations is through administering the survey on Amazon's mechanical turk (mTurk), which is an online crowd-sourcing marketplace in which users can post tasks for other users to complete. Samples collected through mTurk show diversity in terms of profession, age, and education levels, and therefore, may be a better representation of the U.S. workforce.

\section{Practical Implications and Societal Impact}

Given that the use of WRE is a fairly modern phenomenon, many organizations in the U.S. have yet to form any formal policies or procedures surrounding the use of WRE after hours. The results of this study can be useful for company leadership and practitioners aiming to form policies to regulate the use of WRE after hours, and also for employees who wish to better manage their WRE use after work hours. Employees can pay attention to how their perceptions of workplace norms and individual factors, such as telepressure, are influencing their decisions to keep up with WRE. In addition, employees may wish to disconnect their WRE from their smartphones as a first step in decreasing their WRE use.

The degree to which employees feel keeping up with WRE after hours was mandatory was found to play a large role in increasing the likelihood of experiencing burnout symptoms as a result of greater WRE use after hours. This finding can be valuable in modern leadership training materials and programs. Conveying to employees that keeping up with their WRE after hours is not a requirement of the job may result in 
employees willingly checking, reading, or responding to their WRE while "off the clock," which in turn may result in more favorable well-being outcomes. Leaders may also wish to take action on controlling workplace and job factors that may lead to increased WRE use after hours. For example, supervisors or managers could strive to create or maintain healthier workplace norms through establishing clearer rules around keeping up with WRE while at home. In addition, leadership can attempt to more clearly establish the relationship (or lack of a relationship) between WRE use after hours and job performance, or more clearly identify the relevance of WRE to the job, so that employees rely less on their own perceptions of usefulness and the job relevance of keeping up with WRE after hours, and more on concrete workplace rules or policies.

Organizational leadership may also wish to be cautious when assigning company mobile devices, especially those that provide employees access to their WRE. Having a company-issued mobile device may send a signal to employees that they should be "on the clock" at all hours. Although the impact of owning a company-issued mobile device was not assessed in this study, since it was not directly relevant to employees within the present sample, employees' perceptions of owning a company-issued phone should be further explored in future research.

In addition, this study addresses a social issue that is extremely salient for the general public. Employees are gaining insight, through their personal experiences, into the effects of WRE use after hours on their home lives, productivity, and health. Indeed, there have been several lawsuits concerning overtime pay for workers keeping up with work through company-issued smartphones. In addition, journalists for periodicals such as the New York Times and the Wall Street Journal have been gathering compelling 
evidence from surveys and polls about both the positive and negative perceptions of WRE use after work. Many of these conclusions, however, had not been empirically tested. The present study makes a unique contribution to the developing area of WRE use research through identifying factors of the individual, job, and workplace that can influence WRE after hours. Employees wishing to decrease their WRE use after hours may be able to more easily do so if they are able to identify the factors that influence their decision to keep up with their WRE after hours. In addition, keeping up with WRE after hours is commonly viewed as having a negative impact on employee well-being. However, using WRE as a method of managing work demands may be a useful perspective to take if aiming to reduce burnout. Therefore, the findings of this study not only have implications for both researchers and practitioners, but also address social concerns and interests of the general public.

\section{Conclusion}

This study aimed to contribute to the emerging body of research on the effects of work-related technology on employee well-being through examining the antecedents and consequences of WRE use after work hours. Antecedents at the individual, job, and workplace level were found to have relationships with engagement in WRE after work hours, and telepressure, job relevance, and perceived usefulness were found to uniquely explain WRE use behavior. These findings offer insight into the influence of factors related to the individual, job, or workplace, on one's decision to keep up with their WRE after work hours, and take a novel step towards better understanding how specific elements of the individual or environment can influence this behavior. 
In addition, the three dimensions of burnout were examined as outcomes, in order to explore the negative effects of WRE use after hours. Interestingly, keeping up with WRE after hours was found to have a negative relationship with two of three burnout dimensions (i.e., cynicism and reduced personal accomplishment), which was the opposite of the hypothesized direction of these relationships. These findings suggest that perhaps rather than acting as an increase in workload or work demands, the engagement in WRE use after hours is actually functioning as a method to better manage work demands, resulting in more favorable burnout outcomes.

Voluntariness was also found to moderate WRE use after hours' relationships with emotional exhaustion and reduced professional accomplishment, which makes a unique contribution to the emerging research in this area. Based on these findings, organizations may wish to take measures to convey to employees that keeping up with their WRE after hours is not mandatory. This will allow employees who engage in WRE after hours to use this behavior as a strategy to manage work demands rather than allowing this behavior to create additional work demands. Although these findings can help both researchers and practitioners better understand the modern phenomenon of WRE use after work, there is much left to be done in this area of research in order to keep up with the rapid momentum of technological advancement in our modern society. 


\section{REFERENCES}

Abdullah, F., \& Ward, R. (2016). Developing a general extended technology acceptance model for e-learning (GETAMEL) by analysing commonly used external factors. Computers in Human Behavior, 56, 238-256.

Adams, D. A., Nelson, R. R., \& Todd, P. A. (1992). Perceived usefulness, ease of use, and usage of information technology: A replication. MIS Quarterly, 16(2), 227247.

American Psychological Association's Center for Organizational Excellence (2013). Americans stay connected to work on weekends, vacation and even when out sick. Retrieved from http://www.apa.org/news/press/releases/2013/09/connectedwork.aspx

Ariani, D. W. (2012). Leader-member exchanges as a mediator of the effect of job satisfaction on affective organizational commitment: An empirical test. International Journal of Management, 29(1), 46-56.

Bakker, A. B., \& Demerouti, E. (2007). The job demands-resources model: State of the art. Journal of Managerial Psychology, 22(3), 309-328.

Bakker, A. B., Demerouti, E., \& Euwema, M. C. (2005). Job resources buffer the impact of job demands on burnout. Journal of Occupational Health Psychology, 10(2), 170 .

Bakker, A. B., Demerouti, E., \& Schaufeli, W. B. (2002). Validation of the Maslach burnout inventory-general survey: An internet study. Anxiety, Stress \& Coping, $15(3), 245-260$.

Bakker, A. B., Demerouti, E., Taris, T. W., Schaufeli, W. B., \& Schreurs, P. J. (2003). A multigroup analysis of the job demands-resources model in four home care organizations. International Journal of Stress Management, 10(1), 16-38.

Bakker, A. B., Demerouti, E., \& Verbeke, W. (2004). Using the job demands-resources model to predict burnout and performance. Human Resource Management, 43(1), 83-104.

Barber, L. K., \& Jenkins, J. S. (2014). Creating technological boundaries to protect bedtime: Examining work-home boundary management, psychological detachment and sleep. Stress and Health, 30(3), 259-264.

Bandura, A. (1977). Social learning theory. Englewood Cliffs, NJ: Prentice Hall. 
Barber, L. K., \& Santuzzi, A. M. (2014). Please respond ASAP: Workplace telepressure and employee recovery. Journal of Occupational Health Psychology, 20(2), 172189.

Beehr, T. A., Bowling, N. A., \& Bennett, M. M. (2010). Occupational stress and failures of social support: When helping hurts. Journal of Occupational Health Psychology, 15(1), 45.

Behrend, T. S., Sharek, D. J., Meade, A. W., \& Wiebe, E. N. (2011). The viability of crowdsourcing for survey research. Behavior Research Methods, 43(3), 800-813.

Bere, A., \& Rambe, P. (2016). An empirical analysis of the determinants of mobile instant messaging appropriation in university learning. Journal of Computing in Higher Education, 1-27.

Bollen, K. A., \& Long, J. S. (1993). Testing structural equation models. Newbury Park, CA: Sage.

Boneva, B., Kraut, R., \& Frohlich, D. (2001). Using e-mail for personal relationships: The difference gender makes. American Behavioral Scientist, 45(3), 530-549.

Bond, F. W., \& Bunce, D. (2003). The role of acceptance and job control in mental health, job satisfaction, and work performance. Journal of Applied Psychology, 88(6), 1057-1067.

Bond, F. W., \& Flaxman, P. E. (2006). The ability of psychological flexibility and job control to predict learning, job performance, and mental health. Journal of Organizational Behavior Management, 26(1-2), 113-130.

Boswell, W. R., \& Olson-Buchanan, J. B. (2007). The use of communication technologies after hours: The role of work attitudes and work-life conflict. Journal of Management, 33(4), 592-610.

Brauer, M., \& Chaurand, N. (2010). Descriptive norms, prescriptive norms, and social control: An intercultural comparison of people's reactions to uncivil behaviors. European Journal of Social Psychology, 40(3), 490-499.

Bronfenbrenner, U. (1977). Toward an experimental ecology of human development. American Psychologist, 32(7), 513-531.

Burke, R. J., \& Deszca, E. (1986). Correlates of psychological burnout phases among police officers. Human Relations, 39(6), 487-501. 
Chiaburu, D. S., Oh, I., Berry, C. M., Li, N., Gardner, R. G. (2011). The five-factor model of personality traits and organizational citizenship behaviors: A metaanalysis. Journal of Applied Psychology, 96(6), 1140-1166.

Cialdini, R. B., \& Goldstein, N. J. (2004). Social influence: Compliance and conformity. Annual Review of Psychology, 55, 591-621.

Cialdini, R. B., Kallgren, C. A., \& Reno, R. R. (1991). A focus theory of normative conduct: A theoretical refinement and reevaluation of the role of norms in human behavior. Advances in Experimental Social Psychology, 24(20), 201-234.

Clark, S. C. (2002). Communicating across the work/home border. Community, Work \& Family, 5(1), 23-48.

Cohen, J. (1988). Statistical power analysis for the behavioral sciences $\left(2^{\text {nd }}\right.$ ed.). Hillsdale, NJ: Lawrence Erlbaum Associates.

Cordes, C. L., \& Dougherty, T. W. (1993). A review and an integration of research on job burnout. Academy of Management Review, 18(4), 621-656.

Costa, P T. \& McCrae, R. (1992) NEO PI-R professional manual. Odesa, FL: Psychological Assessment Resources.

Dabbish, L. A., \& Kraut, R. E. (2006). Email overload at work: An analysis of factors associated with email strain. Proceedings of the 200620 th Anniversary Conference on Computer Supported Cooperative Work, 431-440.

Dabbish, L. A., Kraut, R. E., Fussell, S., \& Kiesler, S. (2005). Understanding email use: Predicting action on a message. Proceedings of the SIGCHI Conference on Human Factors in Computing Systems, 691-700.

Davis, F. D. (1989). Perceived usefulness, perceived ease of use, and user acceptance of information technology. MIS Quarterly, 13(3), 319-340.

Davis, F. D., Bagozzi, R. P., \& Warshaw, P. R. (1989). User acceptance of computer technology: A comparison of two theoretical models. Management Science, 35(8), 982-1003.

Demerouti, E. (1999). Burnout: Eine Folge Konkreter Abeitsbedingungen bei Dienstleistungs und Produktionstdtigkeiten. (Burnout: A consequence of specific working conditions among human service and production tasks). Frankfurt/Main: Lang. 
Deutsch, M., \& Gerard, H. B. (1955). A study of normative and informational social influences upon individual judgment. The Journal of Abnormal and Social Psychology, 51(3), 629-636.

Donnellan, M. B., Oswald, F. L., Baird, B. M., \& Lucas, R. E. (2006). The mini-IPIP scales: Tiny-yet-effective measures of the Big Five factors of personality. Psychological Assessment, 18(2), 192-203.

Dwyer, D. J., \& Ganster, D. C. (1991). The effects of job demands and control on employee attendance and satisfaction. Journal of Organizational Behavior, 12(7), 595-608.

Etzion, D., Eden, D., \& Lapidot, Y. (1998). Relief from job stressors and burnout: Reserve service as a respite. Journal of Applied Psychology, 83(4), 577-585.

Faul, F., Erdfelder, E., Lang, A. G., \& Buchner, A. (2007). G* Power 3: A flexible statistical power analysis program for the social, behavioral, and biomedical sciences. Behavior Research Methods, 39(2), 175-191.

Fernet, C., Guay, F., \& Senécal, C. (2004). Adjusting to job demands: The role of work self-determination and job control in predicting burnout. Journal of Vocational Behavior, 65(1), 39-56.

Fishbein, M., \& Ajzen, I. (1975). Belief, attitudes, intention, and behavior. An introduction to theory and research. Reading, MA: Addison-Wesley.

Frese, M., \& Fay, D. (2001). Personal initiative: An active performance concept for work in the 21st century. Research in Organizational Behavior, 23, 133-187.

Freudenberger, H. J., \& Richelson, G. (1980). Burnout: The high cost of high achievement. Norwell, MA: Anchor Press.

Ganster, D. C. (1989). Measurement of worker control. Research report for NIOSH (Contract No. 88-79187), 1-19.

Ganster, D. C. (2008). Measurement challenges for studying work-related stressors and strains. Human Resource Management Review, 18(4), 259-270.

Goldberg, L. R. (1992). The development of markers for the big-five factor structure. Psychological Assessment, 4(1), 26.

Goldberg, L. R. (1999). A broad-bandwidth, public domain, personality inventory measuring the lower-level facets of several five-factor models. Personality Psychology in Europe, 7(1), 7-28. 
Golden, A. G. (2013). The structuration of information and communication technologies and work-life interrelationships: Shared organizational and family rules and resources and implications for work in a high-technology organization. Communication Monographs, 80(1), 101-123.

Gosling, S. D., Rentfrow, P. J., \& Swann, W. B. (2003). A very brief measure of the BigFive personality domains. Journal of Research in Personality, 37, 504-528.

Gupta, V., Agarwal, U. A., \& Khatri, N. (2016). The relationships between perceived organizational support, affective commitment, psychological contract breach, organizational citizenship behaviour and work engagement. Journal of Advanced Nursing, 72(11), 2806-2817.

Halbesleben, J. R., \& Bowler, W. M. (2007). Emotional exhaustion and job performance: The mediating role of motivation. Journal of Applied Psychology, 92(1), 93-106.

Haralambos, M., \& Holborn, M. (2000). Sociology: Themes and perspectives $\left(5^{\text {th }}\right.$ Edition). London, England: HarperCollins Publishers Limited.

Hartwick, J., \& Barki, H. (1994). Explaining the role of user participation in information system use. Management Science, 40(4), 440-465.

Hendrickson, A. R., Massey, P. D., \& Cronan, T. P. (1993). On the test-retest reliability of perceived usefulness and perceived ease of use scales. MIS Quarterly, 17(2), 227-230.

Hockey, G. R. J. (1993). Cognitive-energetical control mechanisms in the management of work demands and psychological health. In A. Baddely \& L. Weiskrantz (Eds.), Attention: Selection, awareness, and control (pp. 328-345). Oxford, England: Clarendon Press.

Ilies, R., Fulmer, I. S., Spitzmuller, M., \& Johnson, M. D. (2009). Personality and citizenship behavior: The mediating role of job satisfaction. Journal of Applied Psychology, 94(4), 945-959.

Jerejian, A. C., Reid, C., \& Rees, C. S. (2013). The contribution of email volume, email management strategies and propensity to worry in predicting email stress among academics. Computers in Human Behavior, 29(3), 991-996.

Jackson, J. (1965). Structural characteristics of norms. In I. D. Steiner \& M. Fishbein (Eds.), Current studies in social psychology (pp. 310-309). New York, NY: Holt, Rinehart and Winston.

Jackson, S. E., Schwab, R. L., \& Schuler, R. S. (1986). Toward an understanding of the burnout phenomenon. Journal of Applied Psychology, 71(4), 630. 
Johnson, S. L. (2011). An ecological model of workplace bullying: A guide for intervention and research. Nursing Forum, 46(2), 55-63.

Jordan, M. H., Schraeder, M., Field, H. S., \& Armenakis, A. A. (2007). Organizational citizenship behavior, job attitudes, and the psychological contract. Military Psychology, 19(4), 259-271.

Karasek Jr., R. A. (1979). Job demands, job decision latitude, and mental strain: Implications for job redesign. Administrative Science Quarterly, 24(2), 285-308.

Kenny, D. A., \& McCoach, D. B. (2003). Effect of the number of variables on measures of fit in structural equation modeling. Structural Equation Modeling, 10(3), 333351.

Kieras, D., \& Polson, P. G. (1985). An approach to the formal analysis of user complexity. International Journal of Man-Machine Studies, 22(4), 365-394.

Kreiner, G. E. (2006). Consequences of work-home segmentation or integration: A person-environment fit perspective. Journal of Organizational Behavior, 27, 485507.

Kreiner, G. E., Hillensbe, E. C., \& Sheep, M. L. (2009). Balancing borders and bridges: Negotiating the work-home interface via boundary work tactics. Academy of Management Journal, 52(4), 704-730.

Lapinski, M. K., \& Rimal, R. N. (2005). An explication of social norms. Communication Theory, 15(2), 127-147.

Lazarus, R. S. (1991). Psychological stress in the workplace. Journal of Social Behavior and Personality, 6(7), 1-13.

Lee, R. T., \& Ashforth, B. E. (1996). A meta-analytic examination of the correlates of the three dimensions of job burnout. Journal of Applied Psychology, 81(2), 123-133.

Leiter, M. P., \& Schaufeli, W. B. (1996). Consistency of the burnout construct across occupations. Anxiety, Stress, and Coping, 9(3), 229-243.

Leonard-Barton, D., \& Deschamps, I. (1988). Managerial influence in the implementation of new technology. Management Science, 34(10), 1252-1265.

Maslach, C. (1982). Burnout: The cost of caring. Englewood Cliffs, NJ: Prentice-Hall.

Maslach, C. (1993). Burnout: A multidimensional perspective. In W. B. Schaufeli, C. Maslach, \& T. Marek (Eds.), Professional burnout: Recent developments in theory and research (pp. 19-32). Philadelphia, PA: Taylor \& Francis. 
Maslach, C. (1998). A multidimensional theory of burnout. In C. L. Cooper (Ed.), Theories of organizational stress (pp. 68-85). Oxford, England: Oxford University Press.

Maslach, C., \& Jackson, S. E. (1986). Maslach Burnout Inventory: Second Edition. Palo Alto, CA: Consulting Psychologists Press.

Maslach, C., \& Leiter, M. P. (2008). Early predictors of job burnout and engagement. Journal of Applied Psychology, 93(3), 498.

Maslach, C., Schaufeli, W. B., \& Leiter, M. P. (2001). Job burnout. Annual Review of Psychology, 52(1), 397-422.

O*NET Online (2015). Summary report for: Secretaries and administrative assistants, except legal, medical, and executive. Retrieved from http://www.onetonline.org/link/summary/43-6014.00

Organ, D. W. (1988). A restatement of the satisfaction-performance hypothesis. Journal of Management, 14(4), 547-557.

Organ, D. W., \& Ryan, K. (1995). A meta-analytic review of attitudinal and dispositional predictors of organizational citizenship behavior. Personnel Psychology, 48(4), 775-802.

Park, Y., Fritz, C., \& Jex, S. M. (2011). Relationships between work-home segmentation and psychological detachment from work: The role of communication technology use at home. Journal of Occupational Health Psychology, 16(4), 457-467.

Park, Y., \& Jex, S. M. (2011). Work-home boundary management using communication and information technology. International Journal of Stress Management, 18(2), $133-152$.

Payne, R. D. (2013). Relationship between burnout and organizational citizenship behavior among human service employees (Unpublished doctoral dissertation). Capella University, Minneapolis, MN.

Perrewé, P. L., \& Zellars, K. L. (1999). An examination of attributions and emotions in the transactional approach to the organizational stress process. Journal of Organizational Behavior, 20(5), 739-752.

Pines, A., \& Aronson, E. (1988). Career burnout: Causes and cures. New York, NY: Free Press. 
Podsakoff, P. M., MacKenzie, S. B., Lee, J., \& Podsakoff, N. P. (2003). Common method biases in behavioral research: A critical review of the literature and recommended remedies. Journal of Applied Psychology, 88(5), 879-903.

Podsakoff, N. P., Whiting, S. W., Podsakoff, P. M., \& Blume, B. D. (2009). Individualand organizational-level consequences of organizational citizenship behaviors: A meta-analysis. Journal of Applied Psychology, 94(1), 122-141.

Podsakoff, N. P., Whiting, S. W., Podsakoff, P. M., \& Mishra, P. (2010). Effects of organizational citizenship behaviors on selection decisions in employment interviews. Journal of Applied Psychology, 96(2), 310-326.

Pohl, S., Dal Santo, L., \& Battistelli, A. (2012). Perceived organizational support, job characteristics and intrinsic motivation as antecedents of organizational citizenship behaviours of nurses. Revue Internationale De Psychologie Sociale, 25(3-4), 39-52.

Ragu-Nathan, T. S., Tarafdar, M., Ragu-Nathan, B. S., \& Tu, Q. (2008). The consequences of technostress for end users in organizations: Conceptual development and empirical validation. Information Systems Research, 19(4), 417433.

Reinke, K., \& Chamorro-Premuzic, T. (2014). When email use gets out of control: Understanding the relationship between personality and email overload and their impact on burnout and work engagement. Computers in Human Behavior, 36, 502-509.

Rivis, A., \& Sheeran, P. (2003). Descriptive norms as an additional predictor in the theory of planned behaviour: A meta-analysis. Current Psychology: Developmental, Learning, Personality, Social, 22(3), 218-233.

Ruotsalainen, J. H., Verbeek, J. H., Mariné, A., \& Serra, C. (2014). Preventing occupational stress in healthcare workers. Cochrane Database System Review, 12, $1-115$.

Sabi, H. M., Uzoka, F. M. E., Langmia, K., \& Njeh, F. N. (2016). Conceptualizing a model for adoption of cloud computing in education. International Journal of Information Management, 36(2), 183-191.

Salazar, M. K., \& Beaton, R. (2000). Ecological model of occupational stress: Application to urban firefighters. American Association of Occupational Health Nurses, 48(10), 470-479. 
Salazar, M. K., \& Primomo, J. (1994). Taking the lead in environmental health: Defining a model for practice. AAOHN Journal: Official Journal of the American Association of Occupational Health Nurses, 42(7), 317-324.

Schaufeli, W. B., Bakker, A. B., \& Van Rhenen, W. (2009). How changes in job demands and resources predict burnout, work engagement, and sickness absenteeism. Journal of Organizational Behavior, 30(7), 893-917.

Schaufeli, W. B., Leiter, M. P., Maslach, C., \& Jackson, S. E. (1996). The Maslach Burnout Inventory - General Survey. In C. Maslach, S. E. Jackson, \& M. P. Leiter (Ed.), MBI manual (3rd ed.). Palo Alto, CA: Consulting Psychologists Press.

Schepman, S. B. \& Zarate, M. A. (2008). The relationship between burnout, negative affectivity and organizational citizenship behavior for human service employees. International Journal of Humanities and Social Sciences, 2(4), 242-247.

Shirom, A. (1989). Burnout in work organizations. In C. L. Cooper, \& I. Robertson (Eds.), International review of industrial and organizational psychology (pp. 2548). New York, NY: Wiley.

Shirom, A. (2003). Job-related burnout: A review. In. J. C. Quick \& L. E. Tetrick (Eds.), Handbook of occupational health psychology (pp. 245-264). Washington DC: American Psychological Association.

Sonnentag, S. (2011). Research on work engagement is well and alive. European Journal of Work and Organizational Psychology, 20(1), 29-38.

Sonnentag, S., Binnewies, C., \& Mojza, E. J. (2010). Staying well and engaged when demands are high: The role of psychological detachment. Journal of Applied Psychology, 95(5), 965-976.

Sonnentag, S., Kuttler, I., \& Fritz, C. (2010). Job stressors, emotional exhaustion, and need for recovery: A multi-source study on the benefits of psychological detachment. Journal of Vocational Behavior, 76(3), 355-365.

Spector, P. E. (1986). Perceived control by employees: A meta-analysis of studies concerning autonomy and participation at work. Human Relations, 39(11), 10051016.

Spector, P. E. (1994). Using self-report questionnaires in OB research: A comment of the use of a controversial method. Journal of Organizational Behavior, 15(5), 385392. 
Subramanian, G. H. (1994). A replication of perceived usefulness and perceived ease of use measurement. Decision Sciences, 25(5-6), 863-874.

Szajna, B. (1994). Software evaluation and choice: Predictive evaluation of the technology acceptance instrument. MIS Quarterly, 18(3), 319-324.

Sumecki, D., Chipulu, M., \& Ojiako, U. (2011). Email overload: Exploring the moderating role of the perception of email as a 'business critical' tool. International Journal of Information Management, 31(5), 407-414.

Thommes, M. S. (2015). You've got mail: The effect of workplace telepressure on recovery process and the benefits of mindfulness (Unpublished master's thesis). Maastricht University, Netherlands.

The Radicati Group (2015). Email statistics report, 2015-2018. Retrieved from http://www.radicati.com/wp/wp-content/uploads/2015/02/Email-Statistics-Report2015-2019-Executive-Summary.pdf

Towers, I., Duxbury, L., Higgins, C., \& Thomas, J. (2006). Time thieves and space invaders: Technology, work and the organization. Journal of Organizational Change Management, 19(5), 593-618.

Valcour, P. M., \& Hunter, L. W. (2005). Technology, organizations, and work-life integration. In E. E. Kossek \& S. J. Lambert (Eds.), Work and life integration: Organizational, cultural, and individual perspectives (61-84). Mahwah, NJ: Erlbaum.

Venkatesh, V., \& Davis, F. D. (2000). A theoretical extension of the technology acceptance model: Four longitudinal field studies. Management Science, 46(2), 186-204.

Wright, K. B., Abendschein, B., Wombacher, K., O’Connor, M., Hoffman, M., Dempsey, M., Krull, C., Dewes, A., \& Shelton, A. (2014). Work-related communication technology use outside of regular work hours and work life conflict: The influence of communication technologies on perceived work life conflict, burnout, job satisfaction, and turnover intentions. Management Communication Quarterly, 1-24.

Xanthopoulou, D., Bakker, A. B., Demerouti, E., \& Schaufeli, W. B. (2007). The role of personal resources in the job demands-resources model. International Journal of Stress Management, 14(2), 121-141. 


\section{APPENDIX}

\section{Screening Questions}

Are you employed at Florida International University?

- Yes

- No

How many hours are you typically scheduled to work per week? Please type in a number below.

- $\quad<$ open numerical response $>$

Are you an hourly or salaried worker?

- Hourly worker

- Salaried worker

Please indicate your salary range:

- Below $\$ 20,000$ per year

- $\$ 20,000$ to less than $\$ 30,000$ per year

- $\$ 30,000$ to less than $\$ 40,000$ per year

- $\$ 40,000$ to less than $\$ 50,000$ per year

- $\$ 50,000$ to less than $\$ 60,000$ per year

- $\$ 60,000$ to less than $\$ 70,000$ per year

- $\$ 70,000$ to less than $\$ 80,000$ per year

- $\$ 80,000$ to less than $\$ 90,000$ per year

- $\$ 90,000$ to less than $\$ 100,000$ per year

- $\$ 100,000$ or above per year

\section{Work-Related Email Use after Hours}

Please indicate the degree to which you agree with the following statements.

1. I keep up with work emails after work hours.

2. I send work-related emails after work hours.

3. I check my work-related emails after work hours.

4. I reply to work-related emails after work hours.

5-point Likert scale: "strongly disagree," “disagree," "neither agree nor disagree," "agree," "strongly agree" 


\section{Others' Use}

Please indicate the degree to which you agree with the following statements.

1. My supervisors keep up with their work emails after work hours.

2. My supervisors send work-related emails after work hours.

3. My supervisors check their work-related emails after work hours.

4. My supervisors reply to work-related emails after work hours.

5. My coworkers keep up with their work emails after work hours.

6. My coworkers send work-related emails after work hours.

7. My coworkers check their work-related emails after work hours.

8. My coworkers reply to work-related emails after work hours.

5-point Likert scale: "strongly disagree," "disagree," "neither agree nor disagree," "agree," "strongly agree"

Subjective Expectations of Use (Venkatesh \& Davis, 2000)

Please indicate the degree to which you agree with the following statements.

1. People who influence my behavior think that I should keep up with work-related emails after work hours.

2. People who are important to me think that I should keep up with work-related emails after work hours.

5-point Likert scale: "strongly disagree," "disagree," "neither agree nor disagree," "agree," "strongly agree"

Perceived Usefulness (Venkatesh \& Davis, 2000)

Please indicate the degree to which you agree with the following statements.

1. Keeping up with work-related emails after work hours improves my performance in my job.

2. Keeping up with work-related emails after work hours increases my productivity.

3. Keeping up with work-related emails after work hours enhances my effectiveness in my job.

4. I find that keeping up with work-related emails after work hours is useful for my job.

5-point Likert scale: "strongly disagree," "disagree," "neither agree nor disagree," "agree," "strongly agree" 
Job Relevance (Venkatesh \& Davis, 2000)

Please indicate the degree to which you agree with the following statements.

1. In my job, keeping up with work-related emails after hours is important.

2. Keeping up with work-related emails after hours is relevant to my job.

5-point Likert scale: "strongly disagree," "disagree," "neither agree nor disagree," "agree," "strongly agree"

$\underline{\text { Telepressure }}$ (Barber \& Santuzzi, 2014)

For the following questions, think about how you use work-related emails to communicate with people in your workplace. Please rate how much you agree or disagree with the statements below.

1. It's hard for me to focus on other things when I receive an email from someone.

2. I can concentrate better on other tasks once I've responses to my emails.

3. I can't stop thinking about an email until I've responded.

4. I feel a strong need to respond to others immediately.

5. I have an overwhelming feeling to respond right at the moment I receive a request from someone.

5-point Likert scale: "strongly disagree," "disagree," "neither agree nor disagree," "agree," "strongly agree"

Conscientiousness (Mini IPIP; Donnellan et al., 2006)

Please indicate how accurately each statement below describes you. Describe yourself as you generally are now, not as you wish to be in the future.

1. Get chores done right away.

2. Often forget to put things back in their proper place. (R)

3. Like order.

4. Make a mess of things. (R)

5-point response scale: "very inaccurate," "somewhat inaccurate," "neither accurate now inaccurate," "somewhat accurate," "very accurate" 
Burnout* (Schaufeli, Leiter, Maslach, \& Jackson, 1996)

For each statement below, please select the option that most accurately reflects your response.

1. I feel emotionally drained from my work.

2. I feel I am making an effective contribution to what this organization does.

3. I have become less enthusiastic about my work.

7-point frequency scale: "never," 'a few times per year," "once a month," "a few times per month," "once a week," "a few times per week," "every day"

*Note: Only three samples items of the full 16-item burnout measure are shown here.

Voluntariness (Venkatesh \& Davis, 2000)

Please indicate the degree to which you agree with the following statements.

1. Checking and responding to work-related emails after work hours is voluntary.

2. My supervisor does not require me to keep up with work-related email after hours.

3. Although it might be helpful, keeping up with work-related emails after hours is certainly not compulsory for my job.

5-point Likert scale: "strongly disagree," "disagree," "neither agree nor disagree," "agree," "strongly agree"

\section{Demographic Questions}

What is your age?

- <open numerical response $>$

Please select your gender.

- Male

- Female

How long have you been working in your current position?

- <open numerical response in months and years>

How long have you been employed at your university?

- <open numerical response in months and years> 
How many individuals do you supervise at work? Please enter a number below.

- <open numerical response>

How many individuals are you supervised by at work? Please enter a number below.

- <open numerical response>

Does your office normally allow you to work from home?

- Yes

- No

What is your marital status?

- Married

- Single

- Divorced

- Widowed

- Separated

- Cohabitating (unmarried)

How many children do you have?

- <open numerical response>

Are you currently in a caregiver role (e.g., responsible for caring for children, family members, friends)?

- Yes

- No

On average, what percentage of your daily household tasks, chores, and/or caregiver duties are you responsible for?

- $<0$ to 100 sliding scale $>$

How much help do you receive from your family members of friends to complete household tasks, chores, or errands?

- No help

- A little help

- A moderate amount of help

- A good amount of help

- A large amount of help 
Do you have your work-related email account connected to your smartphone?

- Yes

- No

Do you use your work-related email account for personal purposes (e.g., emailing friends, signing up for promotions)?

- Yes

- No 
VITA

\title{
ARCHANA MANAPRAGADA
}

B.S., Psychology

Nova Southeastern University

Davie, Florida

$2012-2017$

\author{
M.S., Industrial and Organizational Psychology \\ Florida International University \\ Miami, Florida \\ Doctoral Candidate \\ Florida International University \\ Miami, Florida \\ Teaching Assistant \\ Florida International University \\ Miami, Florida
}

\section{PUBLICATIONS AND PRESENTATIONS}

Harari, M. B., Manapragada, A., \& Viswesvaran, C. (In Press). Who thinks they're a big fish in a small pond and why does it matter? A meta-analysis of perceived overqualification. Journal of Vocational Behavior.

Manapragada, A., \& Bruk-Lee, V. (2016). Staying silent about safety issues: Conceptualizing and measuring safety silence motives. Accident Analysis and Prevention, 91, 144-156.

Mesmer-Magnus, J., Manapragada, A., Viswesvaran, C., \& Allen, J. W. (2017). Trait mindfulness at work: A meta-analysis of the personal and professional correlates of trait mindfulness. Human Performance, 1-20.

Nixon, A., Lanz, J. J., Manapragada, A., Bruk-Lee, V., Schantz, A., \& Rodriguez, J. (2015). Modeling relationships between psychological safety climate, job attitudes, safe workplace practices, and injuries. Work \& Stress, 29(4), 401-419.

Casey, T., \& Manapragada, A. (2017, April). Examining the relationships between safety climate, error management, and safety communication. Poster presented at the $32 \mathrm{nd}$ Annual Conference of the Society for Industrial and Organizational Psychology. 
Lanz, J. J., \& Manapragada, A. (2017, April). Putting the "health" in healthcare: Protecting worker safety and wellbeing. Symposium presented at the 32nd Annual Conference of the Society for Industrial and Organizational Psychology.

Manapragada, A., Barrantes, R., \& Bruk-Lee, V. (2016, April). The role of individual differences in a model of workplace safety. Poster presented at the Annual Conference for the Society of Industrial and Organizational Psychology, Anaheim, CA.

Manapragada, A., \& Bruk-Lee, V. (2017, June). The influence of safety silence motives on the relationship between safety communication and safety performance. Paper presented at the American Psychological Association's Work, Stress, and Health Conference, Minneapolis, MN.

Manapragada, A., \& Bruk-Lee, V. (2015, May). Safety silence: The conceptualization and measurement of a new construct. Paper presented at the American Psychological Association's Work, Stress, and Health Conference, Atlanta, GA.

Manapragada, A., Bruk-Lee, V., Lanz, J.J., Falcon, A., \& Schantz, A.D. (2015, April). Speaking up at work: Personality's role in employee voice behavior. Poster presented at the Annual Conference of the Society of Industrial and Organizational Psychology, Philadelphia, PA.

Manapragada, A., Eaton, A. A., Reizer, A., \& Koslowsky, M. (2017, June). Understanding technology-based supplemental work: An examination of workplace, job, and individual-level predictors. Poster presented at the American Psychological Association's Work, Stress, and Health Conference, Minneapolis, MN.

Manapragada, A., Lanz, J.J., Falcon, A., Schantz, A. D., \& Bruk-Lee, V. (2014, May). Breaking the silence: An examination of employee silence behavior. Poster presented at the Annual Conference of the Society for Industrial and Organizational Psychology, Honolulu, HI.

Manapragada, A., Naude, M. N., \& Krauss, A. D. (2017, April). Perceptions of wellbeing climate and burnout in the healthcare industry. Paper presented at the 32nd Annual Conference of the Society for Industrial and Organizational Psychology.

Manapragada, A., \& Viswesvaran, C. (2017, April). Examining the relationship between engagement and technology-assisted supplemental work. Poster presented at the 32nd Annual Conference of the Society for Industrial and Organizational Psychology.

Schantz, A. D., Falcon, A., Lanz, J., Manapragada, A., \& Bruk-Lee, V. (2015, April). Drug, alcohol, and tobacco use to cope with workplace conflict. Paper presented at the Annual Conference of the Society for Industrial and Organizational Psychology, Philadelphia, PA. 